\title{
Clinical value and characteristic of absolute counts of lymphocyte subsets in patients with pulmonary tuberculosis: a large-scale Hospital-Based Study
}

\section{Jianqin Liang}

8th Medical Center of Chinese PLA General Hospital

\section{Xuejuan Bai}

8th Medical Center of Chinese PLA General Hospital

Huiru An

8th Medical Center of Chinese PLA General Hospital

\section{Tao Wang}

8th Medical Center of Chinese PLA General Hospital

\section{Zhongyuan Wang}

8th Medical Center of Chinese PLA General Hospital

\section{Yinping Liu}

8th Medical Center of Chinese PLA General Hospital

\section{Yong Xue}

8th Medical Center of Chinese PLA General Hospital

Xueqiong Wu ( $\nabla$ xueqiongwu@139.com)

8th Medical Center of Chinese PLA General Hospital https://orcid.org/0000-0001-8894-1929

\section{Research Article}

Keywords: Tuberculosis, Lymphocyte subsets, Flow cytometry, Absolute counts, Immunity

Posted Date: September 28th, 2020

DOl: https://doi.org/10.21203/rs.3.rs-81441/v1

License: (c) (i) This work is licensed under a Creative Commons Attribution 4.0 International License. Read Full License 


\section{Abstract \\ Background}

This research aimed to investigate the clinical value and characteristics of peripheral blood lymphocyte subsets in tuberculosis (TB) patients by flow cytometry.

\section{Methods}

The Absolute counts of $\mathrm{T}, \mathrm{CD} 4^{+} \mathrm{T}, \mathrm{CD} 8^{+} \mathrm{T}, \mathrm{NK}, \mathrm{NKT}$ and $\mathrm{B}$ lymphocytes were detected in 217 cases of pulmonary TB (PTB), 163 cases of PTB \& extra-PTB and 65 cases of extra-PTB patients. We analyzed the change characteristic of subset counts with the clinical parameters in PTB and compared the subsets differences among PTB, PTB with extraPTB, and extra-PTB patients.

\section{Results}

The absolute counts of six subsets in $75.3 \%$ of PTB patients were lower than the normal reference range, and $44 \%$ patients showed lower CD4 $4^{+}$lymphocytes. (1) The absolute counts of $\mathrm{T}, \mathrm{CD} 4^{+} \mathrm{T}, \mathrm{CD} 8^{+} \mathrm{T}$ and $\mathrm{B}$ lymphocytes was significantly lower in patients older than 60 years old. (2) The NKT cell counts was significantly lower in female patients than the males; (3) $40.8 \%$ of patients with positive etiological results and $49.2 \%$ of extra-PTB patients showed lower $\mathrm{CD}^{+} \mathrm{T}$ and $\mathrm{NK}$ cell counts below the reference range respectively. (4) The $\mathrm{T}$ and $\mathrm{CD} 4^{+} \mathrm{T}$ lymphocyte counts in PTB with positive IGRA were significantly higher than those with negative IGRA; (5) The T and CD8 ${ }^{+} \mathrm{T}$ cell counts in PTB with positive IgG antibody were decreased; (6) The T, CD4 ${ }^{+}$T, CD8 ${ }^{+} \mathrm{T}$ and B cell counts reduced with the increasing lesion lobe numbers, accelerated ESR, complications with anemia and low serum albumin, and NK cells also decreased in patients with anemia and low serum albumin; and the T, CD ${ }^{+}$, and B cells significantly decreased in PTB patients with diabetes, while NKT increased.

\section{Conclusions}

The immune function in most TB patients is impaired and the absolute counts of lymphocyte subsets could be used as the evidence for immune intervention and monitoring the curative effect.

\section{Background}

Tuberculosis (TB) is a global disease that seriously threatens human health. According to the WHO TB report (1), there were 10 million TB patients, 558,000 patients with multidrug-resistant TB (MDR-TB) or rifampicin-resistant TB worldwide in 2017. A total of 1.3 million patients died of TB. China was one of 22 countries with high TB burden and one of 27 countries with severe TB resistance.

In recent years, it has been gradually recognized that TB is not only a kind of infectious disease, but also an immune disease. Mycobacterium tuberculosis (M. tb) interacts with the host's immune system after infection. The occurrence, development and prognosis of TB are closely related not only to the number and virulence of invasive $M$. $t b$, but also to the immune status and immune responses of the host (2). Therefore, it is important to evaluate the infected hosts' immunity and their clinical immunological characteristics. However, only the following methods can be used to 
evaluate the immune function of TB patients in clinic at present: (1) humoral immune function analysis: mainly detecting anti-TB antibodies in sera; (2) cellular immune function analysis: mainly analyzing percentages and absolute counts of lymphocyte subsets, cytokines (Interferon Gamma Release Assays, IGRA), and delayed-type hypersensitivity reaction (tuberculin skin test). The immune response against TB is principally cell mediated. Flow cytometry (FCM) analysis of peripheral blood lymphocyte subsets is one of the main methods for clinical evaluation of immune function of the subjects, which helps to understand the immune status, immune function and immune balance of TB patients, and provides the basis for immune intervention, curative effect observation and prognosis judgment of TB patients. This detection has been widely used in the patients with hematology, cancer, acquired immune deficiency syndrome, (AIDS) etc., but there are few reports on its application in the TB (3).

According to the expression of cluster of differentiation (CD) antigens on the cell surface, human peripheral blood lymphocyte could be routinely divided into three subsets in clinic: T lymphocyte $\left(C D 3^{+}\right)$, B lymphocyte $\left(C D 19^{+}\right)$and natural killer lymphocyte (NK, $\left.\mathrm{CD} 3^{-} \mathrm{CD} 16^{+} \mathrm{CD} 56^{+}\right)$. Normally, T cells account for more than $65 \%$ of the total lymphocyte count, consisted mainly of a $\mathrm{T}$ cells ( $90 \%-95 \%$ of the total T cells), which are the most important immune effector cells in human beings. T cells mainly include helper/inducible T cells (CD $3^{+} \mathrm{CD} 4^{+} \mathrm{CD} 8^{-}$, also known as $\mathrm{CD} 4^{+} \mathrm{T}$ cells), cytotoxic/inhibitory $\mathrm{T}$ cells $\left(\mathrm{CD} 3^{+} \mathrm{CD} 8^{+} \mathrm{CD} 4^{-}\right.$, also known as $\mathrm{CD} 8^{+} \mathrm{CD} 4^{-}$, or $\mathrm{CD} 8^{+} \mathrm{T}$ cells) and NKT cells $\left(\mathrm{CD} 3^{+} \mathrm{CD} 56^{+} \mathrm{CD} 16^{+}\right)$, etc. Protective cellular immunity against TB is mainly mediated by $\mathrm{CD} 4^{+} \mathrm{T}$ lymphocytes with support from $\mathrm{CD}^{+} \mathrm{T}$ lymphocytes $(4,5)$. The main functions of $\mathrm{CD} 4^{+} \mathrm{T}$ cells are production of cytokines, such as interferon- $\gamma$ (IFN- $\gamma$ ), and immunity reaction against $M$. tb infection by the Th1 response (4). NK cells provide innate protection against $M$. $t b$. It has been reported that NK cells may mediate the killing of intracellular $M$. $t b$ via apoptosis (6). Natural killer T (NKT) cells, which can be identified by the phenotype $C D 3^{+} C D 56{ }^{+}$, have also been shown to participate in the immunity against TB (7). B lymphocytes can transform into plasma cells secreting anti-M. tb antibodies after activation, and assist cellular immune response to play anti-TB role (8).

Despite the pivotal importance of lymphocytes in anti-TB immunity, most researchers studied the changes of lymphocyte subsets only by means of percentage method rather than the absolute counts in TB cases, which had obtained inconsistent results (9-11). Furthermore, there were few reports about clinical studies based on large data in this field, and systematic and complete understanding were absent at present. Therefore, this study aimed to understand the immune status of TB patients by determining the absolute counts of the T lymphocytes, CD4 ${ }^{+}$and CD8 ${ }^{+}$T lymphocytes, NK lymphocytes, NKT lymphocytes, and B lymphocytes in 217 cases of pulmonary TB patients (PTB), 163 cases of PTB with extra-PTB patients and 65 cases of extra-PTB patients by means of flow cytometry, and analyze the characteristics of lymphocyte subsets in PTB patients. And we also discussed the importance of lymphocyte subsets detection in clinical evaluation and treatment of TB patients.

\section{Material And Methods}

\section{Patients}

The study population consisted of 446 TB patients hospitalized in the 8th Medical Center of Chinese PLA General Hospital in China. These patients were enrolled from April to October in 2018, which included 217 cases of PTB, 163 cases of PTB with extra-PTB patients and 65 cases of extra-PTB patients. Of 217 cases of PTB patients, 52 cases were combined with diabetes mellitus and 76 cases with anemia. Major clinical characteristics of the patients are summarized in Table 1. The diagnostic criteria were based on the guidelines of "WS 288-2017 diagnosis standard of pulmonary tuberculosis" and "WS 196-2017 classification standard of tuberculosis" $(12,13)$ (including TB history, 
symptoms, signs, etiological examination, imaging examination, histopathological examination and treatment efficacy). All patients were negative for HIV infection and without receiving immunosuppressive agent.

Table 1

The detailed demographic and clinical information of the study population

\begin{tabular}{|llll|}
\hline Group & Pulmonary TB & Pulmonary \& extra-pulmonary TB & Extra-pulmonary TB \\
\hline Age $($ Mean \pm SD) & $45.4 \pm 19.4$ & $41.8 \pm 19.5$ & $40.1 \pm 15.8$ \\
\hline Male: Female & $135: 82$ & $98: 66$ & $31: 34$ \\
\hline TB types & & & 65 cases \\
\hline Pulmonary TB & 217 cases & 164 cases & 15 cases \\
\hline Tuberculous pleurisy & & 55 cases & 10 cases \\
\hline Endobronchial TB & & 39 cases & 15 cases \\
\hline Bone TB & 18 cases & 6 cases \\
\hline Lymph node TB & 16 cases & 11 cases \\
\hline Tuberculous meningitis & & 14 cases & 1 case \\
\hline Urogenital TB & 10 cases & 1 case \\
\hline Intestinal TB & 8 cases & 5 cases \\
\hline Thoracic TB & 5 cases & 4 cases & \\
\hline Abdominal TB & 2 cases & 1 case & \\
\hline Laryngophthisis & 1 case & \\
\hline Adrenal TB & & & \\
\hline TB polyserositis & & & \\
\hline
\end{tabular}

Blood sample

Blood samples from TB patients were collected as soon as they were hospitalized. $2 \mathrm{ml}$ of venous peripheral blood sample was collected and reversed for mixing 6-8 times in anticoagulant blood vessels.

\section{Absolute counts of blood lymphocyte subsets by flow cytometry}

To measure the absolute counts of lymphocyte subsets, peripheral blood from TB patients were collected. The $50 \mu \mathrm{l}$ of blood was transferred to the BD Trucount tubes (BD, USA, product code: 340334) containing aliquot of $20 \mu \mathrm{l} 6$-color TB NK reagent [including monoclonal antibodies labeled with fluorochromes: anti-CD45 (PerCP-Cy5.5), anti-CD3 (FITC), anti-CD4 (PE-Cy7), anti-CD8 (APC-Cy7), anti-CD16 + CD56 (PE) and anti-CD19 (APC) (BD, USA, product code: 337166)], the samples were homogenized and incubated for $15 \mathrm{~min}$ at room temperature in the dark. Red blood cell in each sample was lysed by adding $450 \mu$ of FACS lysis solution 1:10 diluted by $\mathrm{ddH}_{2} \mathrm{O}$ (Becton Dickinson, product code: 349202) and incubated for $15 \mathrm{~min}$ at room temperature in the dark. Subsequently, samples were acquired using FACS Arial II flow cytometer (BD, San Jose, CA, USA). The definition of each gate for six lymphocyte subsets were shown in Fig. 1. At least 5000 lymphocytes were obtained, and the software Diva was used for data analysis. The absolute counts for each subset were calculated as follows: cell/L= (total number of cells acquired $\times$ total number of Beads) / (total number of beads acquired $\times$ sample volume). 


\section{Collection of clinical data of patients}

We collected the clinical data of 217 cases of simple PTB patients retrospectively, the parameters and information were recorded as follows: the age and gender of patients; medical history; the etiological detection results of $M$. tb including sputum smear, sputum culture, DNA and RNA detection of $M$. tb in sputum; the immunoassay results of interferon-y release assay (IGRA) and serum IgG antibody detection; X-ray and CT results of patients; and blood test results of erythrocyte sedimentation rate (ESR), serum albumin (Alb) and hemoglobin.

Sputum smear was conducted with Ziehl-Neelsen acid-fast staining; sputum culture was performed using BACTEC ${ }^{\text {TM }}$ MGIT $^{\text {TM }} 960$ Mycobacterium Culture and Detection System (Becton Dickinson Company); DNA detection was performed by Mycobacterial Real-time PCR Detection Kit (Capital Bio, Beijing, China,); RNA detection Kit was Isothermal RNA Amplification Assay for M. tb (REMDU Biotechnology, Shanghai, China) using the technique of Simultaneous Amplification and Testing (SAT); IGRAs were performed using the T cell detection kit for tuberculosis infection (ELISA in vitro) (WANTAI Bio-pharm, Beijing, China) or Mycobacterium tuberculosis specific cellular immune response detection kit (ELISPOT in vitro) (Health-Digit, Shanghai, China); serum IgG antibody was detected using Diagnostic Kit for Antibody to Mycobacterium tuberculosis (Colloidal Gold) (Upper Biotech, Shanghai, China)

\section{Statistical analysis}

The data were managed with Excel 2016 (Microsoft, Redmond, WA, USA) and transferred to SPSS16.0 statistical software package (SPSS Corp., Chicago, IL) for statistical analysis. All data are presented as mean \pm standard deviation: The differences between the different groups were analyzed by the Student's t-test or $\mathrm{X}^{2}$-test, where appropriate. P-value $<0.05$ was considered statistically significant.

\section{Results}

\section{Lymphocyte profile in the peripheral blood from patients with pulmonary TB}

As showed in Fig. 2, the absolute counts of T lymphocytes, CD4 ${ }^{+} \mathrm{T}$ cell, CD8 ${ }^{+} \mathrm{T}$ cell, NK cell, NKT cell and B lymphocytes in 39.9\% (152/381), 43.8\% (167/381), 32.8\% (125/381), 41.2\% (157/381), 31.0\% (118/381), and 24.1\% (92/381) PTB patients were lower than the reference range for healthy Chinese respectively (14). 75.3\% (275/381) of PTB patients had lower absolute counts of various types of lymphocyte subsets than the refence range in varying degree. And the absolute counts of $\mathrm{T}, \mathrm{CD} 4^{+}, \mathrm{CD} 8^{+}, \mathrm{NK}, \mathrm{NKT}$, and $\mathrm{B}$ lymphocyte in $22 \mathrm{~TB}$ patients were all lower than the normal ranges simultaneously, in which 12 (55.4\%) cases with hypoproteinemia, 12 (55.4\%) cases with anemia, 12 (55.4\%) cases with liver injury, 8 (36.4\%) cases with leukopenia, and 7 cases (31.8\%) with diabetes.

Variation of absolute counts of lymphocyte subsets with different ages and genders in simple PTB patients

All PTB patients were divided into four age groups, namely $<25,26-44,45-59$, and $<60$ years old, as shown in Fig. 3 and Table 2. The absolute counts of $\mathrm{T}, \mathrm{CD} 4^{+}, \mathrm{CD} 8^{+}, \mathrm{NK}, \mathrm{NKT}$, and $\mathrm{B}$ lymphocyte peaked at 26-44 of age, and then decreased gradually with the increase of age. Especially for $\mathrm{T}, \mathrm{CD} 4^{+}, \mathrm{CD} 8^{+}$, and $\mathrm{B}$ lymphocyte, the declining trend was particularly obvious, their absolute counts in PTB patients over 60 years old were significantly lower than those of patients between 26 and 44 years old ( $p<0.05$, details showed in Table 2). Figures 4 showed that the absolute counts of all 6 subsets in male group were higher than those in female group, but the difference between male group and female group was significant only in NK cell group $(p=0.0257)$. 
Table 2

Comparisons of lymphocyte subset absolute counts among the different groups divided by clinical parameters in 217 simple PTB patients

\begin{tabular}{|c|c|c|c|c|c|c|c|c|}
\hline \multirow[t]{2}{*}{ Groups } & \multirow[t]{2}{*}{ Cases } & \multicolumn{6}{|c|}{ Mean \pm SD of absolute lymphocyte subset counts (cells/ $\mu \mathrm{l}$ ) } & \multirow[t]{2}{*}{$P$ value } \\
\hline & & T subset & $\begin{array}{l}\text { CD4 } \\
\text { subset }\end{array}$ & $\begin{array}{l}\text { CD8 } \\
\text { subset }\end{array}$ & $\begin{array}{l}\text { NK } \\
\text { subset }\end{array}$ & $\begin{array}{l}\text { NKT } \\
\text { subset }\end{array}$ & B subset & \\
\hline \multicolumn{9}{|l|}{ Age } \\
\hline$\leq 25$ & 47 & $\begin{array}{l}1247 \pm \\
425.1^{\text {a1 }}\end{array}$ & $\begin{array}{l}675.5 \pm \\
263.5^{a 2}\end{array}$ & $\begin{array}{l}482.4 \pm \\
181.5^{\mathrm{a} 3} \\
\text { b3 }\end{array}$ & $\begin{array}{l}181.4 \\
\pm \\
110.8\end{array}$ & $\begin{array}{l}64.2 \pm \\
49.5\end{array}$ & $\begin{array}{l}254.5^{ \pm} \\
162.5^{\mathrm{a} 4}\end{array}$ & \multirow{4}{*}{$\begin{array}{l}\text { a1, 0.006; b1, } \\
\text { 0.000; c1, 0.012 } \\
\text { a2, 0.026; b2, } \\
\text { 0.000; c2, 0.029; } \\
\text { d, } 0.044 \\
\text { a3, 0.048; b3, } \\
0.015 \\
\text { a4, 0.000; b4, } \\
0.000 ; c 3,0.005\end{array}$} \\
\hline $26 \sim 44$ & 61 & $\begin{array}{l}1378 \pm \\
733.2 \text { b1 } \\
c 1\end{array}$ & $\begin{array}{l}803.3 \pm \\
460.4 \text { b2 } \\
c 2\end{array}$ & $\begin{array}{l}502.0 \pm \\
313.1^{\text {b3 }}\end{array}$ & $\begin{array}{l}263.4 \\
\pm \\
242.8\end{array}$ & $\begin{array}{l}93.0 \pm \\
97.0\end{array}$ & $\begin{array}{l}250.8 \pm \\
148.5^{b 4}\end{array}$ & \\
\hline $45 \sim 59$ & 53 & $\begin{array}{l}1110 \pm \\
553.3^{c 1}\end{array}$ & $\begin{array}{l}656.1 \pm \\
376.1^{c 2} \\
d\end{array}$ & $\begin{array}{l}409.3 \pm \\
227.0^{\text {a3 }}\end{array}$ & $\begin{array}{l}190.5 \\
\pm \\
122.1\end{array}$ & $\begin{array}{l}88.4 \pm \\
84.6\end{array}$ & $\begin{array}{l}205.5 \pm \\
151.2^{c 3}\end{array}$ & \\
\hline$\geq 60$ & 56 & $\begin{array}{l}935.5 \pm \\
450.2^{a 1} \\
\text { b1 }\end{array}$ & $\begin{array}{l}517.9 \pm \\
263.1^{a 2} \\
b 2, d\end{array}$ & $\begin{array}{l}388.9 \pm \\
236.5\end{array}$ & $\begin{array}{l}219.6 \\
\pm \\
164.4\end{array}$ & $\begin{array}{l}74.1 \pm \\
70.3\end{array}$ & $\begin{array}{l}130.1 \pm \\
89.4^{a 4} \\
b 4, c 3\end{array}$ & \\
\hline \multicolumn{9}{|l|}{ Gender } \\
\hline Male & 136 & $\begin{array}{l}1211.4 \pm \\
599.1\end{array}$ & $\begin{array}{l}690.3 \pm \\
377.5\end{array}$ & $\begin{array}{l}459.6 \pm \\
261.0\end{array}$ & $\begin{array}{l}223.9 \\
\pm \\
150.4\end{array}$ & $\begin{array}{l}90.9^{ \pm} \\
89.5^{a}\end{array}$ & $\begin{array}{l}209.4 \pm \\
152.4\end{array}$ & \multirow[t]{2}{*}{ a, 0.022} \\
\hline Female & 81 & $\begin{array}{l}1078.1 \pm \\
553.4\end{array}$ & $\begin{array}{l}615.3 \pm \\
356.4\end{array}$ & $\begin{array}{l}411.4 \pm \\
228.5\end{array}$ & $\begin{array}{l}207.2 \\
\pm \\
206.7\end{array}$ & $\begin{array}{l}66.1 \pm \\
56.2^{a}\end{array}$ & $\begin{array}{l}206.7 \pm \\
142.9\end{array}$ & \\
\hline \multicolumn{9}{|c|}{$\begin{array}{l}\text { Etiological } \\
\text { examination }\end{array}$} \\
\hline Negative & 71 & $\begin{array}{l}1255 \pm \\
78.09\end{array}$ & $\begin{array}{l}704.5 \pm \\
46.0\end{array}$ & $\begin{array}{l}479.3 \pm \\
34.1\end{array}$ & $\begin{array}{l}208.5 \\
\pm 16.7\end{array}$ & $\begin{array}{l}78.42 \\
\pm 8.7\end{array}$ & $\begin{array}{l}219.2 \pm \\
17.9\end{array}$ & \\
\hline Positive & 125 & $\begin{array}{l}1110 \pm \\
47.41\end{array}$ & $\begin{array}{l}636.5 \pm \\
31.1\end{array}$ & $\begin{array}{l}422.6 \pm \\
20.8\end{array}$ & $\begin{array}{l}214.7 \\
\pm 13.5\end{array}$ & $\begin{array}{l}85.03 \\
\pm 7.7\end{array}$ & $\begin{array}{l}205.6 \pm \\
13.3\end{array}$ & \\
\hline \multicolumn{9}{|c|}{ IGRA results } \\
\hline Negative & 48 & $\begin{array}{l}1005.0 \pm \\
532.0^{\text {a } 1}\end{array}$ & $\begin{array}{l}561.29 \pm \\
297.8^{a 2}\end{array}$ & $\begin{array}{l}388.3 \pm \\
222.7\end{array}$ & $\begin{array}{l}201.8 \\
\pm \\
129.4\end{array}$ & $\begin{array}{l}72.5 \pm \\
69.7\end{array}$ & $\begin{array}{l}191.9 \pm \\
131.9\end{array}$ & \multirow[t]{2}{*}{$\begin{array}{l}a 1,0.0462 \\
a 2,0.023\end{array}$} \\
\hline Positive & 151 & $\begin{array}{l}1223.8 \pm \\
592.0^{a 1}\end{array}$ & $\begin{array}{l}698.7 \pm \\
379.0^{\text {a2 }}\end{array}$ & $\begin{array}{l}466.6 \pm \\
260.4\end{array}$ & $\begin{array}{l}225.3 \\
\pm \\
191.96\end{array}$ & $\begin{array}{l}85.4 \pm \\
83.8\end{array}$ & $\begin{array}{l}217.9 \pm \\
154.9\end{array}$ & \\
\hline \multicolumn{9}{|c|}{ IgG results } \\
\hline Negative & 116 & $\begin{array}{l}1188 \pm \\
618.3^{\text {a1 }}\end{array}$ & $\begin{array}{l}656.4 \pm \\
34.8\end{array}$ & $\begin{array}{l}465.8 \pm \\
25.4 \text { a2 }\end{array}$ & $\begin{array}{l}204.1 \\
\pm 13.2\end{array}$ & $\begin{array}{l}85.7 \pm \\
7.4\end{array}$ & $\begin{array}{l}210.2 \pm \\
14.3\end{array}$ & $\begin{array}{l}\text { a1, } 0.0343 ; a 2, \\
0.0136\end{array}$ \\
\hline
\end{tabular}




\begin{tabular}{|c|c|c|c|c|c|c|c|c|}
\hline \multirow[t]{2}{*}{ Groups } & \multirow[t]{2}{*}{ Cases } & \multicolumn{6}{|c|}{ Mean \pm SD of absolute lymphocyte subset counts (cells/ $\mu \mathrm{l})$} & \multirow[t]{2}{*}{$P$ value } \\
\hline & & T subset & $\begin{array}{l}\text { CD4 } \\
\text { subset }\end{array}$ & $\begin{array}{l}\text { CD8 } \\
\text { subset }\end{array}$ & $\begin{array}{l}\text { NK } \\
\text { subset }\end{array}$ & $\begin{array}{l}\text { NKT } \\
\text { subset }\end{array}$ & B subset & \\
\hline Positive & 57 & $\begin{array}{l}995.2 \pm \\
412.2^{\mathrm{a} 1}\end{array}$ & $\begin{array}{l}594.3 \pm \\
35.4\end{array}$ & $\begin{array}{l}364.8 \pm \\
25.7 \text { a2 }\end{array}$ & $\begin{array}{l}224.9 \\
\pm 22.6\end{array}$ & $\begin{array}{l}79.8 \pm \\
12.2\end{array}$ & $\begin{array}{l}189.9 \pm \\
14.8\end{array}$ & \\
\hline \multicolumn{9}{|l|}{ ESR results } \\
\hline Negative & 91 & $\begin{array}{l}1320 \pm \\
61.1^{\text {a1 }}\end{array}$ & $\begin{array}{l}735 \pm \\
36.7^{\text {a2 }}\end{array}$ & $\begin{array}{l}499.8 \pm \\
29.2^{\text {a3 }}\end{array}$ & $\begin{array}{l}223.5 \\
\pm 14.7\end{array}$ & $\begin{array}{l}83.7 \pm \\
8.3\end{array}$ & $\begin{array}{l}250.6 \pm \\
16.8^{a} 4\end{array}$ & \multirow{2}{*}{$\begin{array}{l}\text { a1, } 0.0003 ; a 2, \\
0.0065 \\
\text { a3, } 0.0034 ; a 4, \\
0.0003\end{array}$} \\
\hline Positive & 106 & $\begin{array}{l}1024 \pm \\
53.1 \text { a1 }\end{array}$ & $\begin{array}{l}594.7 \pm \\
35.3^{\text {a2 }}\end{array}$ & $\begin{array}{l}394.5 \pm \\
21.4^{\text {a3 }}\end{array}$ & $\begin{array}{l}204.1 \\
\pm 14.8\end{array}$ & $\begin{array}{l}81.6 \pm \\
8.1\end{array}$ & $\begin{array}{l}174.5 \pm \\
12.6^{\text {a } 4}\end{array}$ & \\
\hline \multicolumn{9}{|l|}{ Serum Alb } \\
\hline $\begin{array}{l}\text { Low (< } \\
35 \text { g/L) }\end{array}$ & 73 & $\begin{array}{l}955.7 \pm \\
64.3^{a 1}\end{array}$ & $\begin{array}{l}566.2 \pm \\
43.0^{\text {a2 }}\end{array}$ & $\begin{array}{l}358.2 \pm \\
26.7 \text { a3 }\end{array}$ & $\begin{array}{l}184.4 \\
\pm 17.2 \\
\text { a4 }\end{array}$ & $\begin{array}{l}76.3 \pm \\
8.2\end{array}$ & $\begin{array}{l}153.5 \pm \\
16.4^{\text {a5 }}\end{array}$ & \multirow{2}{*}{$\begin{array}{l}\text { a1, <0.0001; } \\
\text { a2,0.0034; a3, } \\
0.0003 ; \\
\text { a4, } 0.0446 ; \text { a }<< \\
0.0001\end{array}$} \\
\hline $\begin{array}{l}\text { Normal } \\
(35-50 \mathrm{~g} / \mathrm{L})\end{array}$ & 116 & $\begin{array}{l}1290 \pm \\
52.0^{\text {a1 }}\end{array}$ & $\begin{array}{l}723.2 \pm \\
32.2^{\text {a } 2}\end{array}$ & $\begin{array}{l}492.4 \pm \\
23.9 \text { a3 }\end{array}$ & $\begin{array}{l}228.1 \\
\pm 13.3 \\
a 4\end{array}$ & $\begin{array}{l}87.6 \pm \\
8.3\end{array}$ & $\begin{array}{l}242.4 \pm \\
13.0^{\text {a } 5}\end{array}$ & \\
\hline \multicolumn{9}{|l|}{$\begin{array}{l}\text { Chest } \\
\text { radiography }\end{array}$} \\
\hline 1 lobe & 47 & $\begin{array}{l}1501.0 \pm \\
663.2 \mathrm{a} 1 \\
\mathrm{~b} 1\end{array}$ & $\begin{array}{l}845.7 \pm \\
490.9 \text { a2, } \\
\text { b2 }\end{array}$ & $\begin{array}{l}571.9 \pm \\
224.3^{\text {a3 }} \\
\text { b3 }\end{array}$ & $\begin{array}{l}241.4 \\
\pm \\
126.9\end{array}$ & $\begin{array}{l}95.9 \pm \\
91.0\end{array}$ & $\begin{array}{l}275.2 \pm \\
170.6^{a 4}\end{array}$ & \multirow{3}{*}{$\begin{array}{l}a 1,0.000 ; b 1, \\
0.002 \\
\text { a2, } 0.000 ; b 2, \\
0.016 \\
\text { a3, } 0.000 ; b 3, \\
0.001 \\
\text { a4, } 0.000 ; b 4, \\
0.038\end{array}$} \\
\hline $2 \sim 3$ lobes & 59 & $\begin{array}{l}1165.6 \pm \\
495.5 \text { b1 }\end{array}$ & $\begin{array}{l}675.6 \pm \\
327.5^{b 2}\end{array}$ & $\begin{array}{l}416.1 \pm \\
174.5^{b 3}\end{array}$ & $\begin{array}{l}233.8 \\
\pm \\
228.7\end{array}$ & $\begin{array}{l}75.2 \pm \\
66.0\end{array}$ & $\begin{array}{l}222.6 \pm \\
134.4 \text { b4 }\end{array}$ & \\
\hline $4 \sim 5$ lobes & 111 & $\begin{array}{l}1032.5 \pm \\
540.2^{\text {a1 }}\end{array}$ & $\begin{array}{l}584.9 \pm \\
300.0^{\text {a2 }}\end{array}$ & $\begin{array}{l}408.4 \pm \\
280.0^{\text {a3 }}\end{array}$ & $\begin{array}{l}196.8 \\
\pm \\
157.5\end{array}$ & $\begin{array}{l}77.3 \pm \\
80.0\end{array}$ & $\begin{array}{l}174.5 \pm \\
134.3^{\mathrm{a} 4} \\
\text { b4 }\end{array}$ & \\
\hline \multicolumn{9}{|l|}{ Cavities } \\
\hline 0 & 73 & $\begin{array}{l}1310.5 \pm \\
652.2^{a 1}\end{array}$ & $\begin{array}{l}719.9 \pm \\
406.0\end{array}$ & $\begin{array}{l}520.9 \pm \\
300.8^{a 2}, \\
b\end{array}$ & $\begin{array}{l}199.2 \\
\pm \\
215.0\end{array}$ & $\begin{array}{l}229.1 \\
\pm \\
162.2\end{array}$ & $\begin{array}{l}1310.5 \pm \\
652.2\end{array}$ & \multirow[t]{4}{*}{$\begin{array}{l}\text { a1, 0.014; a2, } \\
0.001 ; b, 0.01\end{array}$} \\
\hline $1 \sim 2$ & 76 & $\begin{array}{l}1138.5 \pm \\
445.7\end{array}$ & $\begin{array}{l}651.6 \pm \\
282.1\end{array}$ & $\begin{array}{l}416.5 \pm \\
181.0^{b}\end{array}$ & $\begin{array}{l}243.3 \\
\pm \\
144.6\end{array}$ & $\begin{array}{l}200.1 \\
\pm \\
111.4\end{array}$ & $\begin{array}{l}1138.5 \pm \\
445.7\end{array}$ & \\
\hline $3 \sim 4$ & 24 & $\begin{array}{l}1089.9 \pm \\
550.3\end{array}$ & $\begin{array}{l}606.5 \pm \\
322.7\end{array}$ & $\begin{array}{l}457.9 \pm \\
274.3\end{array}$ & $\begin{array}{l}202.7 \\
\pm \\
159.4\end{array}$ & $\begin{array}{l}231.5 \\
\pm \\
152.1\end{array}$ & $\begin{array}{l}1089.9 \pm \\
550.3\end{array}$ & \\
\hline$\geq 5$ & 44 & $\begin{array}{l}1035.6 \pm \\
662.4^{a 1}\end{array}$ & $\begin{array}{l}633.82 \pm \\
454.0\end{array}$ & $\begin{array}{l}365.8 \pm \\
226.0^{a 2}\end{array}$ & $\begin{array}{l}206.5 \\
\pm \\
154.5\end{array}$ & $\begin{array}{l}180.8 \\
\pm \\
174.0\end{array}$ & $\begin{array}{l}1035.6 \pm \\
662.4\end{array}$ & \\
\hline $\begin{array}{l}\text { Treatment } \\
\text { course }\end{array}$ & & & & & & & & \\
\hline
\end{tabular}




\begin{tabular}{|c|c|c|c|c|c|c|c|c|}
\hline \multirow[t]{2}{*}{ Groups } & \multirow[t]{2}{*}{ Cases } & \multicolumn{6}{|c|}{ Mean \pm SD of absolute lymphocyte subset counts (cells/ $\mu$ l) } & \multirow[t]{2}{*}{ P value } \\
\hline & & T subset & $\begin{array}{l}\text { CD4 } \\
\text { subset }\end{array}$ & $\begin{array}{l}\text { CD8 } \\
\text { subset }\end{array}$ & $\begin{array}{l}\text { NK } \\
\text { subset }\end{array}$ & $\begin{array}{l}\text { NKT } \\
\text { subset }\end{array}$ & B subset & \\
\hline $\begin{array}{l}\text { Initial } \\
\text { treated }\end{array}$ & 166 & $\begin{array}{l}1205.6 \pm \\
596.3\end{array}$ & $\begin{array}{l}687.2 \pm \\
385.1\end{array}$ & $\begin{array}{l}458.3 \pm \\
254.1\end{array}$ & $\begin{array}{l}229.1 \\
\pm \\
189.7\end{array}$ & $\begin{array}{l}79.0 \pm \\
74.5\end{array}$ & $\begin{array}{l}212.0 \pm \\
150.6\end{array}$ & \\
\hline Retreated & 51 & $\begin{array}{l}1054.7 \pm \\
534.2\end{array}$ & $\begin{array}{l}597.0 \pm \\
305.7\end{array}$ & $\begin{array}{l}405.5 \pm \\
240.6\end{array}$ & $\begin{array}{l}175.6 \\
\pm \\
104.0\end{array}$ & $\begin{array}{l}86.5 \pm \\
92.9\end{array}$ & $\begin{array}{l}201.0 \pm \\
139.5\end{array}$ & \\
\hline \multicolumn{9}{|l|}{ TB types } \\
\hline PTB & 217 & $\begin{array}{l}1170.1 \pm \\
584.6\end{array}$ & $\begin{array}{l}666.0 \pm \\
369.4\end{array}$ & $\begin{array}{l}445.9 \pm \\
251.5\end{array}$ & $\begin{array}{l}216.5 \\
\pm \\
174.7\end{array}$ & $\begin{array}{l}80.8 \pm \\
79.0\end{array}$ & $\begin{array}{l}209.4 \pm \\
147.8\end{array}$ & \\
\hline $\begin{array}{l}\text { PTB \& extra- } \\
\text { PTB }\end{array}$ & 163 & $\begin{array}{l}1144.4 \pm \\
543.4\end{array}$ & $\begin{array}{l}639.5 \pm \\
330.4\end{array}$ & $\begin{array}{l}446.29 \\
\pm 245.16\end{array}$ & $\begin{array}{l}210.3 \\
\pm \\
166.5\end{array}$ & $\begin{array}{l}90.44 \\
\pm 85.7\end{array}$ & $\begin{array}{l}207.7 \pm \\
294.8\end{array}$ & \\
\hline Extra-PTB & 65 & $\begin{array}{l}1118.7 \pm \\
510.9\end{array}$ & $\begin{array}{l}626.7 \pm \\
346.3\end{array}$ & $\begin{array}{l}435.37 \\
\pm 216.19\end{array}$ & $\begin{array}{l}179.1 \\
\pm \\
122.4\end{array}$ & $\begin{array}{l}81.06 \\
\pm 73.7\end{array}$ & $\begin{array}{l}217.7 \pm \\
184.0\end{array}$ & \\
\hline \multicolumn{9}{|l|}{$\begin{array}{l}\text { Diabetes } \\
\text { mellitus }\end{array}$} \\
\hline YES & 52 & $\begin{array}{l}1003.0 \pm \\
436.1^{\mathrm{a} 1}\end{array}$ & $\begin{array}{l}584.3 \pm \\
296.1\end{array}$ & $\begin{array}{l}376.7 \pm \\
187.9 \\
\text { a2 }\end{array}$ & $\begin{array}{l}187.6 \\
\pm \\
130.0\end{array}$ & $\begin{array}{l}100.5 \\
\pm \\
106.0 \\
\text { a3 }\end{array}$ & $\begin{array}{l}159.8 \pm \\
110.9^{\text {a } 4}\end{array}$ & $\begin{array}{l}\text { a1, 0.005; a2, } \\
0.022 ; \text { a3, 0.0386; } \\
\text { a4, } 0.001\end{array}$ \\
\hline NO & 165 & $\begin{array}{l}1222.8 \pm \\
615.9 \text { a1 }\end{array}$ & $\begin{array}{l}691.8 \pm \\
386.8\end{array}$ & $\begin{array}{l}467.8 \pm \\
265.1^{\text {a2 }}\end{array}$ & $\begin{array}{l}225.7 \\
\pm \\
186.0\end{array}$ & $\begin{array}{l}74.55 \\
\pm 67.6 \\
\text { a3 }\end{array}$ & $\begin{array}{l}225.7 \pm \\
186.0^{\mathrm{a} 4}\end{array}$ & \\
\hline \multicolumn{9}{|l|}{ Anemia } \\
\hline YES & 76 & $\begin{array}{l}953.5 \pm \\
63.8^{\text {a } 1}\end{array}$ & $\begin{array}{l}562.1 \pm \\
43.6^{\text {a2 }}\end{array}$ & $\begin{array}{l}355.7 \pm \\
24.0 \text { a3 }\end{array}$ & $\begin{array}{l}186.1 \\
\pm 18.2 \\
\text { a4 }\end{array}$ & $\begin{array}{l}68.6 \pm \\
6.6\end{array}$ & $\begin{array}{l}165.6 \pm \\
17.4^{\text {a5 }}\end{array}$ & $\begin{array}{l}\text { a1,<0.0001; a2, } \\
0.0018 ; a 3, \\
0.0001 ;\end{array}$ \\
\hline NO & 119 & $\begin{array}{l}1299 \pm \\
51.5^{\mathrm{a} 1}\end{array}$ & $\begin{array}{l}727.0 \pm \\
31.1^{\text {a2 }}\end{array}$ & $\begin{array}{l}499.0 \pm \\
24.4^{\text {a3 }}\end{array}$ & $\begin{array}{l}228.3 \\
\pm 12.6 \\
a 4\end{array}$ & $\begin{array}{l}91.7 \pm \\
8.5\end{array}$ & $\begin{array}{l}240.6 \pm \\
12.9 \text { a5 }\end{array}$ & $\begin{array}{l}\text { a4, 0.0499; a5, } \\
0.0005\end{array}$ \\
\hline
\end{tabular}

\section{Variation of absolute counts of lymphocyte subsets with etiological detection results in simple PTB patients}

The etiological detection results of $M$. tb included sputum smear, sputum culture, DNA, and RNA detection of $M$. tb in sputum. The patients with positive results in any detection above-mentioned were classified as the positive group and the others as the negative group. We compared the lymphocyte subsets absolute counts between the two groups. We found that there was no significant difference between the two groups, as showed in Table 2. But the percentages of patients with lower absolute counts of $\mathrm{T}, \mathrm{CD} 4^{+}, \mathrm{CD}^{+}, \mathrm{NK}$, and NKT lymphocyte than the reference ranges were higher 
in the etiological positive group than in the etiological negative group. Especially for the CD $8^{+} \mathrm{T}$ lymphocyte, it was significantly different between two groups $(p=0.0295)$, as showed in Table 3. 
Table 3

Comparisons of Cases (\%) below the standard range of lymphocyte subset absolute counts [14] among the different groups divided by clinical parameters in 217 cases simple PTB patients

\begin{tabular}{|c|c|c|c|c|c|c|c|c|}
\hline \multirow[t]{2}{*}{ Groups } & \multirow{2}{*}{$\begin{array}{l}\text { Total } \\
\text { Cases }\end{array}$} & \multicolumn{6}{|c|}{ Cases (\%) below the standard range } & \multirow{2}{*}{$\begin{array}{l}P \\
\text { value }\end{array}$} \\
\hline & & $\begin{array}{l}\text { T subset } \\
(<955 \\
\text { cells/ } \mu l)\end{array}$ & $\begin{array}{l}\text { CD4 } \\
\text { subset } \\
\text { (<550 } \\
\text { cells/ } / \mathrm{l})\end{array}$ & $\begin{array}{l}\text { CD8 } \\
\text { subset } \\
(<320 \\
\text { cells/ul) }\end{array}$ & $\begin{array}{l}\text { NK subset } \\
(<150 \\
\text { cells/ } \mu \mathrm{l})\end{array}$ & 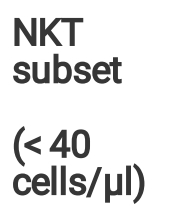 & $\begin{array}{l}\text { B subset } \\
(<90 \\
\text { cells/ } \mu l)\end{array}$ & \\
\hline \multicolumn{9}{|l|}{$\begin{array}{l}\text { Pathogenic } \\
\text { examination }\end{array}$} \\
\hline Negative & 71 & $28(39.4 \%)$ & $31(43.7 \%)$ & $\begin{array}{l}18(25.4 \%) \\
a\end{array}$ & $26(36.6 \%)$ & $23(32.4 \%)$ & $15(21.1 \%)$ & \multirow[t]{2}{*}{$\begin{array}{l}a, \\
0.0295\end{array}$} \\
\hline Positive & 125 & $54(43.2 \%)$ & $58(46.4 \%)$ & $\begin{array}{l}51(40.8 \%) \\
a\end{array}$ & $49(39.2 \%)$ & $42(33.6 \%)$ & $26(20.8 \%)$ & \\
\hline \multicolumn{9}{|l|}{ IGRA results } \\
\hline Negative & 48 & $\begin{array}{l}26 \\
(54.2 \%)^{a 1}\end{array}$ & $\begin{array}{l}23 \\
(47.9 \%)\end{array}$ & $\begin{array}{l}22 \\
(45.8 \%)\end{array}$ & $\begin{array}{l}16 \\
(33.3 \%)\end{array}$ & $\begin{array}{l}24 \\
(50.0 \%)^{\text {a2 }}\end{array}$ & $\begin{array}{l}11 \\
(22.9 \%)\end{array}$ & \multirow{2}{*}{$\begin{array}{l}\text { a1, } \\
0.0362 \\
\text { a2, } \\
0.0079\end{array}$} \\
\hline Positive & 151 & $\begin{array}{l}56 \\
(37.1 \%)^{a 1}\end{array}$ & $\begin{array}{l}62 \\
(41.1 \%)\end{array}$ & $\begin{array}{l}47 \\
(31.1 \%)\end{array}$ & $\begin{array}{l}58 \\
(38.4 \%)\end{array}$ & $\begin{array}{l}44 \\
(29.1 \%)^{\text {a2 }}\end{array}$ & $\begin{array}{l}33 \\
(21.8 \%)\end{array}$ & \\
\hline \multicolumn{9}{|l|}{ Treatment } \\
\hline $\begin{array}{l}\text { Initial } \\
\text { treated }\end{array}$ & 166 & $\begin{array}{l}65 \\
(39.2 \%)\end{array}$ & $\begin{array}{l}71 \\
(42.8 \%)\end{array}$ & $\begin{array}{l}53 \\
(31.9 \%)\end{array}$ & $\begin{array}{l}63 \\
(38.0 \%)\end{array}$ & $\begin{array}{l}57 \\
(34.3 \%)\end{array}$ & $\begin{array}{l}33 \\
(19.9 \%)\end{array}$ & \\
\hline Retreated & 51 & $\begin{array}{l}25 \\
(49.0 \%)\end{array}$ & $\begin{array}{l}26 \\
(51.0 \%)\end{array}$ & $\begin{array}{l}23 \\
(45.1 \%)\end{array}$ & $\begin{array}{l}22 \\
(43.1 \%)\end{array}$ & $\begin{array}{l}18 \\
(35.3 \%)\end{array}$ & $\begin{array}{l}14 \\
(27.5 \%)\end{array}$ & \\
\hline \multicolumn{9}{|l|}{ TB types } \\
\hline PTB & 217 & $\begin{array}{l}92 \\
(42.4 \%)\end{array}$ & $\begin{array}{l}97 \\
(44.7 \%)\end{array}$ & $\begin{array}{l}77 \\
(35.5 \%)\end{array}$ & $\begin{array}{l}83 \\
(38.2 \%)\end{array}$ & $\begin{array}{l}75 \\
(34.6 \%)\end{array}$ & $\begin{array}{l}48 \\
(22.1 \%)\end{array}$ & \\
\hline $\begin{array}{l}\text { PTB \& extra- } \\
\text { PTB }\end{array}$ & 163 & $\begin{array}{l}62 \\
(37.8 \%)\end{array}$ & $\begin{array}{l}69 \\
(42.1 \%)\end{array}$ & $\begin{array}{l}49 \\
(29.9 \%)\end{array}$ & $\begin{array}{l}74 \\
(45.1 \%)\end{array}$ & $\begin{array}{l}43 \\
(26.2 \%)\end{array}$ & $\begin{array}{l}44 \\
(26.8 \%)\end{array}$ & \\
\hline Extra-PTB & 65 & $\begin{array}{l}29 \\
(44.6 \%)\end{array}$ & $\begin{array}{l}27 \\
(41.5 \%)\end{array}$ & $\begin{array}{l}22 \\
(33.8 \%)\end{array}$ & $\begin{array}{l}32 \\
(49.2 \%)\end{array}$ & $\begin{array}{l}23 \\
(35.4 \%)\end{array}$ & $\begin{array}{l}18 \\
(27.7 \%)\end{array}$ & \\
\hline \multicolumn{9}{|l|}{$\begin{array}{l}\text { Diabetes } \\
\text { mellitus }\end{array}$} \\
\hline YES & 52 & $\begin{array}{l}30 \\
(57.7 \%)^{a 1}\end{array}$ & $\begin{array}{l}31 \\
(59.6 \%)^{a 2}\end{array}$ & $\begin{array}{l}25 \\
(48.1 \%)^{a 3}\end{array}$ & $\begin{array}{l}24 \\
(46.2 \%)\end{array}$ & $\begin{array}{l}16 \\
(30.8 \%)\end{array}$ & $\begin{array}{l}18 \\
(34.6 \%)^{a 4}\end{array}$ & \multirow{2}{*}{$\begin{array}{l}\text { a1, } \\
0.0065 \\
\text { a2, } \\
0.0131\end{array}$} \\
\hline \multirow[t]{2}{*}{ NO } & 165 & $\begin{array}{l}60 \\
(36.4 \%)^{a 1}\end{array}$ & $\begin{array}{l}66 \\
(40.0 \%)^{a 2}\end{array}$ & $\begin{array}{l}51 \\
(30.9 \%)^{a 3}\end{array}$ & $\begin{array}{l}61 \\
(37.0 \%)\end{array}$ & $\begin{array}{l}59 \\
(35.8 \%)\end{array}$ & $\begin{array}{l}29 \\
(17.6 \%)^{a 4}\end{array}$ & \\
\hline & & & & & & & & $\begin{array}{l}\text { a3, } \\
0.0236\end{array}$ \\
\hline
\end{tabular}




\begin{tabular}{|c|c|c|c|c|c|c|c|c|}
\hline \multirow{2}{*}{$\begin{array}{l}\text { Groups } \\
\text { Anemia }\end{array}$} & \multirow{2}{*}{$\begin{array}{l}\text { Total } \\
\text { Cases }\end{array}$} & \multicolumn{6}{|c|}{ Cases (\%) below the standard range } & \multirow{2}{*}{$\begin{array}{l}P \\
\text { value }\end{array}$} \\
\hline & & T subset & & & NK subset & & B subset & \\
\hline \multirow[t]{2}{*}{ YES } & 76 & $\begin{array}{l}\text { (465559\%) } \\
\text { zells/ } / \text { l) }\end{array}$ & $\begin{array}{l}\text { subset } \\
45(59.2 \%) \\
(2550 \\
\text { cells/ } / \mu l)\end{array}$ & 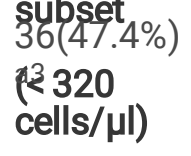 & $\begin{array}{l}3915503 \%) \\
\text { zells/ } / \mathrm{ll})\end{array}$ & $\begin{array}{l}\text { subset } \\
30(39.5 \%) \\
(<40 \\
\text { cells/ } / \mu l)\end{array}$ & 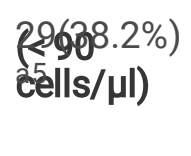 & $\begin{array}{l}\text { a1, } \\
0.0002\end{array}$ \\
\hline & & & & & & & & 0.0016 \\
\hline \multirow[t]{3}{*}{ NO } & \multirow[t]{3}{*}{119} & \multirow{3}{*}{$\begin{array}{l}37(31.1 \%) \\
\text { a1 }\end{array}$} & \multirow{3}{*}{$\begin{array}{l}43(36.1 \%) \\
\text { a2 }\end{array}$} & \multirow{3}{*}{$\begin{array}{l}33(27.7 \%) \\
\text { a3 }\end{array}$} & \multirow{3}{*}{$\begin{array}{l}36(30.3 \%) \\
\text { a4 }\end{array}$} & \multirow[t]{3}{*}{$35(29.4 \%)$} & \multirow{3}{*}{$\begin{array}{l}11(9.2 \%) \\
\text { a5 }\end{array}$} & 0.0052 \\
\hline & & & & & & & & $\begin{array}{l}\text { a4, } \\
0.0032\end{array}$ \\
\hline & & & & & & & & $\begin{array}{l}\text { a5, } \\
0.0000\end{array}$ \\
\hline
\end{tabular}

\section{Association of absolute counts of lymphocyte subsets with IGRAs in PTB patients}

As showed in Fig. 5 and Table 2, the mean absolute counts of 6 subsets in PTB patients were higher in the IGRApositive group than those in the IGRA-negative group, especially for $\mathrm{T}$ and $\mathrm{CD} 4^{+}$lymphocyte, the difference were significant ( $p=0.0462, P=0.023$ respectively). Table 3 showed that for all six subsets, the percentages of patients with absolute counts below the reference ranges in the IGRA-negative group were higher than those in the IGRApositive group. Especially for $T$ and NKT cells, the differences were significant ( $p=0.0362,0.0079$ respectively).

\section{Association of absolute counts of lymphocyte subsets with serum anti-TB IgG tests in PTB patients}

According to the results of serum anti-TB IgG antibody test, TB patients were divided into IgG-negative group and IgGpositive group. The absolute counts of $\mathrm{T}$ lymphocyte and $\mathrm{CD} 8^{+} \mathrm{T}$ lymphocyte in IgG-negative group were significantly higher than those in IgG-positive group ( $P=0.0343,0.0136$ respectively), while the numbers of $B$ lymphocyte did not increase significantly in IgG-positive group, as showed in Table 2 and Fig. 6.

\section{Association of absolute counts of lymphocyte subsets with ESR in PTB patients}

According to the ESR value, the PTB patients were divided into two groups: ESR-negative group whose ESR value was within the reference range (male, $0-15 \mathrm{~mm} / \mathrm{h}$; female, $0-20 \mathrm{~mm} / \mathrm{h}$ ) and ESR-positive group whose ESR value was higher than the reference range. After comparison, it was found that the absolute counts of T cells, $\mathrm{CD} 4^{+} \mathrm{T}$ cells, CD $8^{+}$ T cells, and B cells were significantly different between two groups, and the counts in ESR-negative group was significantly higher than those in ESR-positive group $(P=0.0003,0.0065,0.0034$ and 0.0003 respectively). However, there was no significant difference between NK cells and NKT cells. The results were showed in Table 2 and Fig. 7.

\section{Association of absolute counts of lymphocyte subsets with serum Albumin in PTB patients}

As showed in Table 2 and Fig. 8, we divided the PTB patients into two groups according to the results of serum albumin values. The normal group had normal albumin value $(35-50 \mathrm{~g} / \mathrm{L})$ and the abnormal group had lower 
albumin value $(<35 \mathrm{~g} / \mathrm{L})$. After comparison, we found that the absolute counts of T lymphocyte, $\mathrm{CD} 4^{+} \mathrm{T}$ lymphocyte, $\mathrm{CD}^{+} \mathrm{T}$ lymphocyte, NK cell, and B lymphocyte were significantly lower in abnormal group than those in the normal group $(P<0.0001, P=0.0034, P=0.0003, P=0.0446, P<0.0001$ respectively). But there was no significant difference in NKT cells between the two groups.

\section{Association of absolute counts of lymphocyte subsets with chest radiography in PTB patients}

The imaging data of patients were observed from two perspectives. Firstly, the patients were divided into three groups according to the numbers of lesion lobe: (1) one lobe group: lesions involving one lobe; (2) 2-3 lobes group: lesions involving 2-3 lobes; (3) 4-5 lobes group: lesions involving 4-5 lobes. The absolute counts of T lymphocyte, CD4 ${ }^{+}$ and $\mathrm{CD}^{+} \mathrm{T}$ lymphocyte were higher in one lobe group than those in 2-3 lobes and 4-5 lobes groups, and B lymphocytes in one lobe and 2-3 lobes groups were significantly higher than those in 4-5 lobes group ( $P$ values showed in Table 2). The absolute counts of NK and NKT cells also showed the decreasing trend with the severity of the lesion, but there was no significant difference among the groups (as shown in Figs. 9A and Table 2). Secondly, the patients were divided into four groups according to whether there were cavities and the numbers of cavities: (1) 0 cavity group; (2) 1-2 cavity group; (3) 3-4 cavities group; (4) $\geq 5$ cavities group. The absolute counts of T lymphocytes, $\mathrm{CD} 4^{+}$lymphocytes, and $\mathrm{CD} 8^{+}$lymphocytes were the highest in the no cavity group and showed a downward trend with the increase of the number of cavities. The absolute count of $T$ lymphocyte in 0 cavity group was significantly higher than that in $\geq 5$ cavities group $(P=0.014)$, and the absolute count of CD8 ${ }^{+}$lymphocyte in the 0 cavity group was significantly higher than that in $1-2$ cavity group and $\geq 5$ cavities group $(P=0.001,0.01$ respectively), while there was no obvious change among the other four lymphocyte subsets. (as showed in Figs. 9b and Table 2).

\section{Differences of lymphocyte subsets between initial-treated and retreated PTB patients}

The absolute counts of $\mathrm{T}, \mathrm{CD} 4{ }^{+} \mathrm{T}, \mathrm{CD} 8{ }^{+} \mathrm{T}$, NK, and $\mathrm{B}$ lymphocytes in retreated patients were lower than those in initial treated patients, and NKT cells in retreated patients were higher than those in initial treated patients, there were no significant difference $(p>0.05)$ (as showed in Figs. 10 and Table 2). Table 3 showed that the percentages of patients with absolute counts below the reference range were higher in the retreated group than those in the initial treated group for each of the six cell subsets.

\section{Influence of diabetes mellitus (DM) on the absolute counts of lymphocyte subsets}

Figure 11 and Table 2 showed that the absolute counts of $\mathrm{T}, \mathrm{CD} 8^{+} \mathrm{T}$, and B lymphocyte were significantly lower in PTB patients with $\mathrm{DM}$ than those without $\mathrm{DM}(\mathrm{P}=0.005,0.022,0.001$ respectively), while the absolute count of NKT lymphocyte was just the reverse $(P=0.0386)$. Table 3 showed that the percentages of patients with $D M$, whose $T$, $\mathrm{CD}^{+}, \mathrm{CD} 8^{+}$and $\mathrm{B}$ lymphocyte counts were below the reference range, were significantly higher than those of patients without $\mathrm{DM}(\mathrm{P}=0.0065,0.0131,0.0236,0.0093$ respectively).

\section{Influence of Anemia on the absolute counts of lymphocyte subsets}


According to the hemoglobin value, we divided patients into two groups. The normal group had normal value (male, 120-165 g/L; female, 110-150 g/L) and the anemia group had lower hemoglobin value (male, < $120 \mathrm{~g} / \mathrm{L} ;$ female, < $110 \mathrm{~g} / \mathrm{L}$ ). Figures 12 and 2 showed that the absolute counts of all lymphocyte subsets in PTB patients with anemia were lower than those without anemia, in which $\mathrm{T}, \mathrm{CD} 4^{+}, \mathrm{CD} 8^{+}$, NK and $\mathrm{B}$ lymphocytes showed significant differences ( $P<0.0001, P=0.0018, P=0.0001, P=0.0499, P=0.0005$ respectively). Table 3 showed that the percentages in the patients with anemia, whose $\mathrm{T}, \mathrm{CD} 4^{+}, \mathrm{CD} 8^{+}, \mathrm{NK}$ and $\mathrm{B}$ lymphocyte were below the reference ranges, were significantly higher than those in patients without anemia $(P=0.0002,0.0016,0.0052,0.0032,0.0000$ respectively).

\section{Influence of the lesion location on the absolute counts of lymphocyte subsets}

The mean absolute counts of six lymphocyte subsets showed no significant differences among PTB patients, PTB complicated with extra-PTB patients and extra-PTB patients $(P>0.05)$, as showed in Table 2 . Furthermore, the absolute count of NK cells was maximal in PTB patients and minimal in extra-PTB patients. Table 3 showed that NK cell absolute counts in $49.2 \%$ extra-PTB patients were below the reference range, and the proportion was quite high.

\section{Discussion}

\section{Lymphocyte profiles in the peripheral blood of TB patients}

Most researchers have studied changes of lymphocyte subsets by means of proportion method in peripheral blood of TB patients, and the results were inconsistent. In some studies, the percentages of CD4 ${ }^{+} \mathrm{T}$ cells were decreased, while the percentages of $\mathrm{CD}^{+} \mathrm{T}$ cells were unchanged (15). Some studies showed that $\mathrm{CD} 4^{+} \mathrm{T}$ and NK cells were reduced while $\mathrm{CD} 8^{+} \mathrm{T}$ and $\mathrm{CD} 19^{+} \mathrm{B}$ cells were increased, especially in advanced or disseminated TB (11). Morais-Papini et al. reported that the absolute numbers of NK cells, NKT cells, CD4 ${ }^{+} \mathrm{T}$ cells and $\mathrm{CD} 19^{+} \mathrm{B}$ cells in the TB group decreased significantly when compared to the controls, the percentage of $\mathrm{CD} 19^{+} \mathrm{B}$ cells and NKT cells also reduced, but the percentage of $\mathrm{CD}^{+} \mathrm{T}$ cells increased (16). Guglielmetti et al. observed reduction in the absolute numbers of CD $4^{+} \mathrm{T}$ cells but no difference in the percentage of these cells (9). A study from Mexico reported that the percentages and absolute numbers of B cells were significantly lower in pulmonary TB patients than in healthy donors, the percentages and absolute numbers of T cells were similar in TB patients and healthy donors, and no significant differences in percentages of $\mathrm{CD}^{+}$or $\mathrm{CD} 8^{+} \mathrm{T}$ cells between TB patients and healthy donors (17). We have noted that high percentage of lymphocyte subsets does not mean a high absolute count. A false high proportion may be due to the reduction of other lymphocyte subsets, and the proportions can be completely kept in the normal rage when all the lymphocyte subset counts decreased or increased simultaneously. In our study, the absolute counts of T lymphocytes, $\mathrm{CD}^{+}, \mathrm{CD}^{+}, \mathrm{NK}, \mathrm{NKT}$, and $\mathrm{B}$ lymphocytes based on large clinical data were analyzed, and we found that the counts of each subsets hardly exceed the reference range, and $75.3 \%$ of TB patients had one or more of the six subsets below the reference range (14). These results showed that TB patients displayed an altered lymphocyte profile in the peripheral blood. Therefore, we still need absolute counts of these subsets based on large data to draw a definite conclusion.

\section{Lymphocyte subsets and clinical features}

Tollerud believed that the count fluctuation of $\mathrm{CD} 4^{+}, \mathrm{CD} 8^{+} \mathrm{T}$ cells would not exceed $10 \%$ from 20 to 70 age years old in healthy people (18). But in our patients studied, the absolute counts of six cell subsets were at a high level in the 26-44 age group and then decreased with the increase of age after 45 years old, and the absolute counts of CD $4^{+} \mathrm{T}$

Page $13 / 29$ 
cell subsets was particularly affected by age. We speculated that the pathogenesis for young TB patients ( $<26$ years old) may be related to insufficiency of immune cells; for middle aged patients (26-44 years old), the pathogenesis may be increased infection opportunities; for old patients ( $>60$ years old), their immune function had decreased to a low level, which were manifested by the lowest absolute counts of lymphocyte subsets. Therefore, the old age was a key factor affecting the immune status of TB patients. The fifth national TB epidemiological sampling survey in China found that the proportion of elderly TB patients (> 60 years old) was as high as $48.8 \%$ (19). Other study also manifested that $T$ and $B$ lymphocyte number in elderly TB patients were significantly decreased, and their immune function was lower than that in young and middle-aged patients, which directly affected the treatment effect and cure time of elderly patients (20). Therefore, during the treatment course of senile TB patents, in addition to using chemicals to kill $M$. $t b$, the clinicians should pay more attention to the immune regulation of patients, such as giving the immunoregulator to improve cellular immune function, which may be helpful to control disease. Gender factor also had a certain impact on the immunity of patients, the lymphocyte subset counts especially NKT cells in the males was higher than female, which was not completely consistent with that the male was susceptible to TB genetically and the TB incidence in the male was significantly higher than that in the female (19). This may be due to that the reduction of lymphocyte counts are not the only determinant leading to TB.

Although the average absolute counts of each subset were not significantly affected by the etiological factor, the percentage of TB patient with $\mathrm{CD}^{+} \mathrm{T}$ lymphocyte counts lower than the reference range was obviously higher in etiological positive patients $(40.8 \%)$ than that in negative patients $(25.4 \%)$, which may be due to that CD $8^{+} \mathrm{T}$ cells play an important part in protective immunity against $M$. tb and can limit pathogen growth by lysis of $M$. tb-infected cells (21). Therefore, we speculated that the patients confirmed with positive etiological detection results may have insufficient $\mathrm{CD}^{+} \mathrm{T}$ cell immune function, which brings challenges to the control on $M$. $t b$ spread.

The IGRAs have been widely used in clinical auxiliary diagnosis of TB. However, IGRAs have certain false-negative rates in TB patients (22). In our study, the average count in each subset in PTB patients were higher in IGRA-positive group than in IGRA-negative group, especially $\mathrm{T}$ lymphocyte and CD4 ${ }^{+} \mathrm{T}$ lymphocyte. In IGRA-negative group, the $\mathrm{T}$ and NKT lymphocyte counts below the reference range were in $54.2 \%$ and $50.0 \%$ patients respectively. Therefore, in clinic, if there is a suspicious TB patient with negative IGRA result, it is necessary to distinguish whether it is truenegative, not infected with $M$. $t b$, or false-negative due to insufficient lymphocyte count or functional deficiency. It has been reported that lymphocyte subsets were strongly associated with immune response in both QFT-Plus and T-SPOT, and the patients with $\mathrm{CD} 4^{+} \mathrm{T}$ cell $\geq 650 / \mathrm{L}$ and $\mathrm{CD} 8^{+} \mathrm{T}$ cell $\geq 400 / \mathrm{L}$ had significantly higher positivity rates in both QFT-Plus and T-SPOT, which was a good evidence of our view (23).

Cellular immunity has been considered to play a key role in anti-TB immunity, however the roles of humoral immunity are unclear in regulating the immune response against $M$. $t b(8)$, but some studies showed that $B$ cells also played a role in anti-TB immunity by antibody interacting with cellular immunity (24). In our study the absolute counts of B lymphocyte did not show significant difference between the IgG-positive and IgG-negative group, but the absolute counts of $\mathrm{T}$ and $\mathrm{CD} 8^{+} \mathrm{T}$ lymphocyte decreased significantly in the IgG-positive group. We cannot fully explain this result, but previous studies (25) have shown that B lymphocytes induced by $M$. tb antigens can differentiate into efficient and short-lived plasma cells and secrete specific antibodies to play an anti-TB role; some of them can differentiate into long-lived memory B cells, when they encounter pathogens again, they can differentiate into new plasma cells and memory B cells quickly, and produce a large number of antibodies. Therefore, when the immune response shifted from Th1 to Th2 in TB patients, B cells differentiated into plasma cells to secrete antibodies, which leaded to the reduction of $\mathrm{B}$ cell in peripheral blood. 
Owing to the negative charge of sialic acid on the surface of erythrocytes membrane, erythrocytes can repel each other and keep the distance of about $25 \mathrm{~nm}$ between each other, and they can disperse, suspend and sink slowly ex vivo. The increase of fibrinogen and immunoglobulin in the plasma leads to a marked increase of erythrocyte sedimentation rate (ESR) in TB patients. We found that the absolute counts of $\mathrm{T}$ cells, $\mathrm{CD} 4^{+} \mathrm{T}$ cells, $\mathrm{CD} 8^{+} \mathrm{T}$ cells and $B$ cells were lower in patients with elevated ESR, while NK and NKT cells were almost unaffected. Because the ESR of TB patients can reflect the severity of the infectious disease to some extent $(26,27)$, we speculated that the counts of $\mathrm{T}, \mathrm{CD} 4^{+} \mathrm{T}, \mathrm{CD} 8^{+} \mathrm{T}$, and $\mathrm{B}$ lymphocyte can better reflect the severity of the disease.

X-ray or CT lesion grading for pulmonary involvement was adopted for disease assessment. In our study, the absolute counts of $\mathrm{T}, \mathrm{CD} 4^{+} \mathrm{T}, \mathrm{CD} 8^{+} \mathrm{T}$, and $\mathrm{B}$ lymphocyte decreased significantly with the increase of the numbers of pulmonary lobes involved; and the absolute counts of $\mathrm{T}$ and $\mathrm{CD} 8^{+} \mathrm{T}$ cell had a greater impact on whether there were cavities or not. It had been reported that the numbers of $\mathrm{T}_{1} \mathrm{CD}^{+}(16,28), \mathrm{CD} 8^{+}$, and $\mathrm{B}$ lymphocyte $(16)$ in patients with unilateral pulmonary lobe lesions were higher than those in patients with bilateral pulmonary lobe lesions, which was consistent with our results. Thus, insufficiency of lymphocyte count has a great impact on the progression and severity of TB and the lymphocyte subset detection is important for TB patients with extensive lesion.

NK cells are not only the first barrier of anti-TB immunity in human, but also play an important regulatory role in the anti-TB immune responses (29). In our study, the NK cell absolute counts below the reference range were in $49.2 \%$ extra-PTB patients, which was higher than the PTB patients. We speculated that the insufficient number of NK cells may be associated with the extrapulmonary dissemination of TB.

\section{Lymphocyte subsets and complications}

Among 22 PTB patients with six subset counts all lower than the reference ranges, most of them had diabetes mellitus, hypoproteinemia, anemia and liver injury. Therefore, we further studied the lymphocyte subsets changes influenced by diabetes, anemia and low serum albumin.

Diabetes mellitus and active TB interact with each other through blood glucose level, immunity and other factors, forming a reciprocal vicious circle $(30,31)$. On one hand, the metabolic disorder and immune injury in patients with diabetes mellitus promote the incidence and development of TB (30); on the other hand, TB also aggravate metabolic disorder of diabetic patients (30), nearly $13 \%$ of pulmonary TB patients complicated with diabetes (32), which poses a serious threat to the lives of patients (33). We found that the TB patients complicated with diabetes mellitus had lower $\mathrm{T}, \mathrm{CD} 4^{+}, \mathrm{CD} 8^{+}$, and $\mathrm{B}$ lymphocytes counts, and other study also showed that coincident diabetes altered the cellular subset distribution of T cells, B cells, dendritic cells and monocytes in active TB (34). We also found that the NKT cells were higher in TB patients complicated with diabetes. NKT is a unique subset of T lymphocytes, having both $T$ cell receptors and NK cell receptors on their cell surfaces. NKT cells are functionally distinct from conventional CD ${ }^{+}$and $\mathrm{CD} 8^{+} \mathrm{T}$ cells, responding rapidly to lipid rather than peptide antigens, and secreting large amounts of Th1 and Th2 cytokines (35). It was reported that NKT cells significantly increased in TB patients complicated with type 2 diabetes mellitus (36), which was consistent with our results. The reason may be due to the high bacillary burden existed in these patients (37).

In this study, the $\mathrm{T}, \mathrm{CD} 4^{+}, \mathrm{CD} 8^{+}, \mathrm{NK}$, and $\mathrm{B}$ cells in TB patients with anemia and low serum albumin were significantly decreased. The albumin was synthesized and secreted to extracellular by liver cells instead of being reserved in liver. Normal albumin level can represent the normal liver function and reflect the nutrition and health status of the host to a certain extent. 
Based on all the data above, we think that it is necessary to evaluate the immune status of TB patients by lymphocyte subsets detection. Especially for those complicated with diabetes mellitus, hypoproteinemia, anemia, and liver injury, the lymphocyte subsets detection can help clinicians make comprehensive judgments and formulate treatment plans suitable for individuals. If necessary, immune intervention can be provided to these patients to promote the recovery of immune function.

\section{Conclusion}

The absolute counts of $\mathrm{T}, \mathrm{CD} 4^{+} \mathrm{T}, \mathrm{CD} 8^{+} \mathrm{T}$, and $\mathrm{B}$ lymphocyte in TB patients decreased with aging, high ESR, the aggravation of imaging lesions, and complications with diabetes, low Alb and anemia; the absolute counts of $\mathrm{T}$ and $\mathrm{CD} 4^{+} \mathrm{T}$ cells obviously decreased in IGRA-negative TB patients; the absolute counts of NK cells decreased significantly in TB patients complicated with low Alb and anemia. These results confirm that the immune defense function in most TB patients is impaired, and the absolute counts of lymphocyte subsets could be used as the evidence for immune intervention and monitoring the curative effect. However, only lymphocyte subsets counts cannot meet the clinical needs well, it is necessary to find new function indicators to guide clinical diagnosis and treatment of TB.

\section{Abbreviations}

TB: tuberculosis; PTB:pulmonary TB; MDR-TB:multidrug-resistant TB; M. tb:Mycobacterium tuberculosis; IGRA:Interferon Gamma Release Assays; FCM:Flow cytometry; CD:cluster of differentiation; IFN- $ү$ :interferon-ץ; NKT:Natural killer T lymphocyte; ESR:erythrocyte sedimentation rate; Alb:albumin

\section{Declarations}

\section{Availability of data and materials}

All the data from this manuscript is publicly available.

\section{Ethics approval and consent to participate}

The study protocol was approved by the Research Ethics Committee of the 8th Medical Center of Chinese PLA General Hospital. The signed informed consent was obtained from all participants before the investigation.

\section{Consent for publication}

Not applicable

\section{Competing interests}

All authors of this paper declare that there is no conflict of interest in this study or in reporting the findings described in this manuscript.

\section{Funding}


This work was supported by grants from the Thirteen-Fifth Mega-Scientific Project on "prevention and treatment of AIDS, viral hepatitis and other infectious diseases [No. 2013ZX10003003-005; No. 2017ZX10201301-007-001], the Key Project of the 8th Medical Center of Chinese PLA General Hospital [No.2018ZD-005], and Military Medical Innovation Project [No. 18CXZ028].

\section{Authors' contributions}

XQW planned and designed the project; JQL, XJB performed experiments and wrote the manuscript; JQL, HRA and XJB analyzed the data and performed statistical analyses; JQL, HRA, TW and ZYW collected the samples; YPL and YX carried out the FCM experiments and collected the clinical data of the subjects. All authors read and approved the final manuscript.

\section{Acknowledgements}

Not Applicable.

\section{References}

1. WHO. Global Tuberculosis Report 2018. 2018.

2. Anca D, Reece ST, Kaufmann SHE. For better or for worse: the immune response against Mycobacterium tuberculosis balances pathology and protection. Immunol Rev. 2015;240(1):235-51.

3. Lyadova IV, Panteleev AV. Th1 and Th17 Cells in Tuberculosis: Protection, Pathology, and Biomarkers. Mediators Inflamm. 2015;2015(7):1-13.

4. Boom WH, Canaday DH, Fulton SA, Gehring AJ, Rojas RE, Torres M. Human immunity to M-tuberculosis: T cell subsets and antigen processing. Tuberculosis. 2003;83(1):98-106.

5. Stenger S, Modlin RL. T cell mediated immunity to Mycobacterium tuberculosis. Curr Opin Microbiol. 1999;2(1):89-93.

6. Sia JK, Georgieva M, Rengarajan J. Innate Immune Defenses in Human Tuberculosis: An Overview of the Interactions between Mycobacterium tuberculosis and Innate Immune Cells. Journal of Immunology Research. 2015;2015(11):747543.

7. Sadaovalle I, Chiba A, Gonzales A, Brenner MB, Behar SM. Innate Invariant NKT Cells Recognize Mycobacterium tuberculosis- Infected Macrophages, Produce Interferon-ү, and Kill Intracellular Bacteria. Plos Pathogens. 2008;4(12):e1000239.

8. Maglione PJ, Xu J, Chan J. B Cells Moderate Inflammatory Progression and Enhance Bacterial Containment upon Pulmonary Challenge with Mycobacterium tuberculosis. J Journal of Immunology. 2007;178(11):7222-34.

9. Guglielmetti L, Cazzadori A, Conti M, Boccafoglio F, Vella A, Ortolani R, et al. Lymphocyte subpopulations in active tuberculosis: association with disease severity and the QFT-GIT assay. International Journal of Tuberculosis. 2013;17(6):825-8.

10. Deveci F, Akbulut HH, Celik I, Muz MH, Ilhan F. Lymphocyte subpopulations in pulmonary tuberculosis patients. Mediators Inflamm. 2006;2006(2):89070.

11. Wu YE, Zhang SW, Peng WG, Li KS, Li K, Jiang JK, et al. Changes in Lymphocyte Subsets in the Peripheral Blood of Patients with Active Pulmonary Tuberculosis. J Journal of International Medical Research. 2009;37(6):1742. 
12. (NHFPC). NHaFPCoC. WS 288-2017 diagnosis standard of pulmonary tuberculosis. 2017.

13. (NHFPC). NHaFPCoC. WS 196-2017 classification standard of tuberculosis. 2017.

14. Zhu L, Wang J. Reference values on blood lymphocyte immunophenotype in healthy Chinese adult. Chinese Journal of Laboratory Medicine. 1998(4):223-6.

15. Uppal SS, Tewari SC, Verma S, Dhot PS. Comparison of CD4 and CD8 lymphocyte counts in HIV-negative pulmonary TB patients with those in normal blood donors and the effect of antitubercular treatment: Hospitalbased flow cytometric study. Cytometry Part B Clinical Cytometry. 2010;61B(1):20-6.

16. Morais-Papini TF, Coelho-Dos-Reis JGA, Wendling APB, do Vale Antonelli LR, Wowk PF, Bonato VLD, et al. Systemic Immunological changes in patients with distinct clinical outcomes during Mycobacterium tuberculosis infection. Immunobiology. 2017;222(11):1014-24.

17. Hernandez J, Velazquez C, Valenzuela O, Robles-Zepeda R, Ruiz-Bustos E, Navarro M, et al. Low number of peripheral blood B lymphocytes in patients with pulmonary tuberculosis. Immunol Investig. 2010;39(3):197-205.

18. Tollerud DJ, Clark JW, Brown LM, Neuland CY, Pankiw-Trost LK, Blattner WA, et al. The influence of age, race, and gender on peripheral blood mononuclear-cell subsets in healthy nonsmokers. J Clin Immunol. 1989;9(3):214-22.

19. Lixia Wang SC, Mingting Chen. The fifth national tuberculosis epidemiological sampling survey report in 2010. Chinese Journal of Tuberculosis Prevention. 2012;34(8):485-508.

20. Hui Liu XZ, Xinli Huang R, Liu H, An Y, Wang. T cell subsets analysis and dynamic changes of active pulmonary tuberculosis patients of different ages. Journal of Hebei Medical University. 2016;37(8):889-92.

21. Stenger S. Cytolytic T cells in the immune response to mycobacterium tuberculosis. Scand J Infect Dis. 2001;33(7):483-7.

22. Nguyen DT, Teeter LD, Graves J, Graviss EA. Characteristics Associated with Negative Interferon-gamma Release Assay Results in Culture-Confirmed Tuberculosis Patients, Texas, USA, 2013-2015. Emerging infectious diseases. 2018;24(3):534 - 40.

23. Igari H, Ishikawa S, Nakazawa T, Oya Y, Futami H, Tsuyuzaki M, et al. Lymphocyte subset analysis in QuantiFERON-TB Gold Plus and T-Spot.TB for latent tuberculosis infection in rheumatoid arthritis. Journal of infection chemotherapy: official journal of the Japan Society of Chemotherapy. 2018;24(2):110-6.

24. Khera AK, Afkhami S, Lai R, Jeyanathan M, Zganiacz A, Mandur T, et al. Role of B Cells in Mucosal VaccineInduced Protective CD8 + T Cell Immunity against Pulmonary Tuberculosis. Journal of immunology (Baltimore, Md: 1950). 2015;195(6):2900-7.

25. Ochsenbein AF, Pinschewer DD, Sierro S, Horvath E, Hengartner H, Zinkernagel RM. Protective long-term antibody memory by antigen-driven and $\mathrm{T}$ help-dependent differentiation of long-lived memory $\mathrm{B}$ cells to short-lived plasma cells independent of secondary lymphoid organs. Proc Natl Acad Sci USA. 2000;97(24):13263-8.

26. Ukpe IS, Southern L. Erythrocyte sedimentation rate values in active tuberculosis with and without HIV coinfection. South African medical journal = Suid-Afrikaanse tydskrif vir geneeskunde. 2006;96(5):427-8.

27. Sudprasert W, Piyapromdee U, Lewsirirat S. Neurological Recovery Determined by C-Reactive Protein, Erythrocyte Sedimentation Rate and Two Different Posterior Decompressive Surgical Procedures: A Retrospective Clinical Study of Patients with Spinal Tuberculosis. Journal of the Medical Association of Thailand = Chotmaihet thangphaet. 2015;98(10):993-1000.

28. Aksu K, EK, ŞP, AO ZG. Lymphocyte Subgroups in Different Forms of Tuberculosis. Tur Toraks Der. 2012;13:1-5.

29. Vankayalapati R, Klucar P, Wizel B, Weis SE, Samten B, Safi H, et al. NK cells regulate CD8 + T cell effector function in response to an intracellular pathogen. Journal of immunology (Baltimore, Md: 1950). 2004;172(1):130-7.

Page 18/29 
30. O'Garra A, Redford PS, McNab FW, Bloom Cl, Wilkinson RJ, Berry MP. The immune response in tuberculosis. Annu Rev Immunol. 2013;31:475-527.

31. Basir MS, Habib SS, Zaidi SMA, Khowaja S, Hussain H, Ferrand RA, et al. Operationalization of bi-directional screening for tuberculosis and diabetes in private sector healthcare clinics in Karachi, Pakistan. BMC Health Serv Res. 2019;19(1):147.

32. Blanco-Guillot F, Delgado-Sanchez G, Mongua-Rodriguez N, Cruz-Hervert P, Ferreyra-Reyes L, Ferreira-Guerrero E, et al. Molecular clustering of patients with diabetes and pulmonary tuberculosis: A systematic review and metaanalysis. PloS one. 2017;12(9):e0184675.

33. Gizaw M, Harries AD, Ade S, Tayler-Smith K, Ali E, Firdu N, et al. Diabetes mellitus in Addis Ababa, Ethiopia: admissions, complications and outcomes in a large referral hospital. Public health action. 2015;5(1):74-8.

34. Kumar NP, Moideen K, Dhakshinraj SD, Banurekha VV, Nair D, Dolla C, et al. Profiling leucocyte subsets in tuberculosis-diabetes co-morbidity. Immunology. 2015;146(2):243-50.

35. Sada-Ovalle I, Chiba A, Gonzales A, Brenner MB, Behar SM. Innate invariant NKT cells recognize Mycobacterium tuberculosis-infected macrophages, produce interferon-gamma, and kill intracellular bacteria. PLoS pathogens. 2008;4(12):e1000239.

36. Zhang Q, Xiao HP, Cui HY, Sugawara I. Significant increase in natural-killer T cells in patients with tuberculosis complicated by type 2 diabetes mellitus. J Int Med Res. 2011;39(1):105-11.

37. Sridhar CB, Kini U, Subhash K. Comparative cytological study of lymph node tuberculosis in HIV-infected individuals and in patients with diabetes in a developing country. Diagn Cytopathol. 2002;26(2):75-80.

\section{Figures}

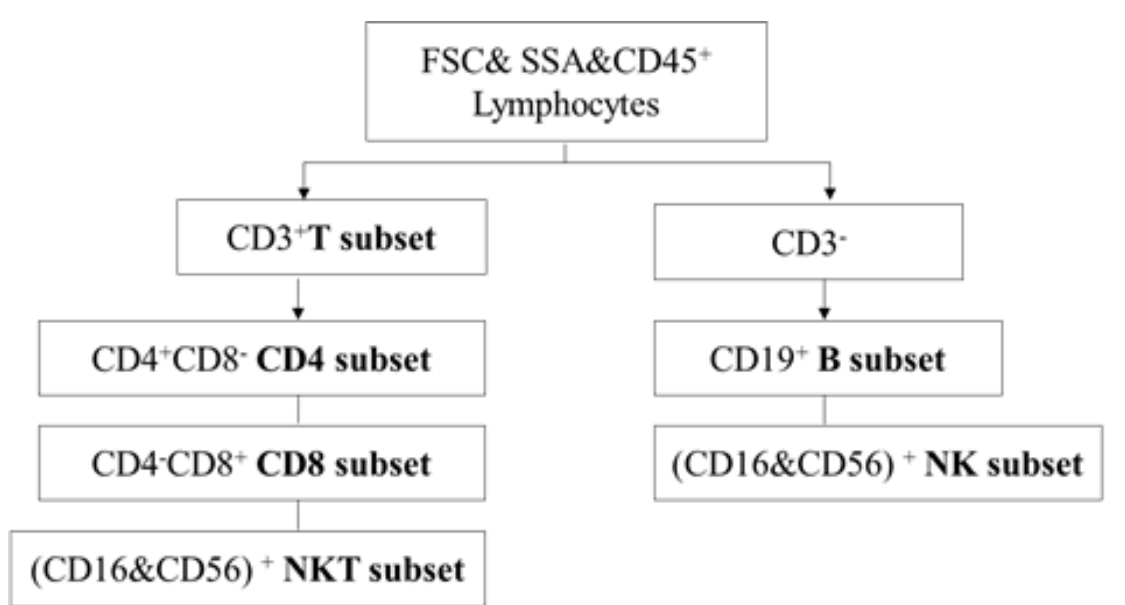

\section{Figure 1}

BD 6-color TBNK reagent including monoclonal antibodies labeled with fluorochromes: anti-CD45 (PerCP-Cy5.5), antiCD3 (FITC), anti-CD4 (PE-Cy7), anti-CD8 (APC-Cy7), anti-CD16+CD56 (PE) and anti-CD19 (APC). 


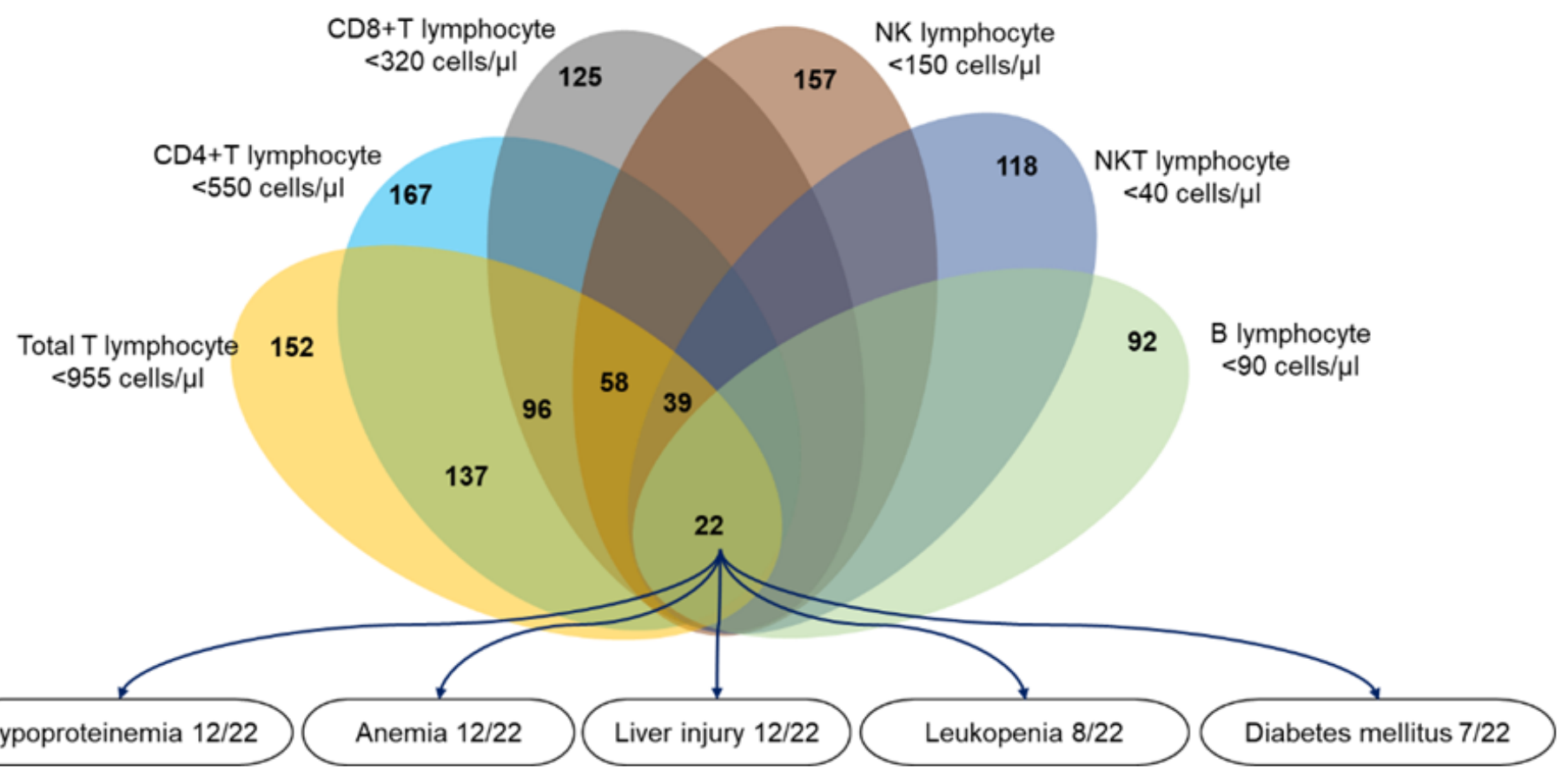

Figure 2

Lymphocyte profile in the peripheral blood from patients with pulmonary TB. Among 379 cases of pulmonary TB, $75.3 \%$ (275 cases) of pulmonary TB patients had lower absolute counts of various type of lymphocyte subsets than the reference range in varying degrees, $44 \%$ of pulmonary TB patients had lower CD4+T cell number than the reference range, and the counts of T cell, CD4+ T cell, CD8+ T cell, NK cell, NKT cell and B cell in 22 patients were all lower.

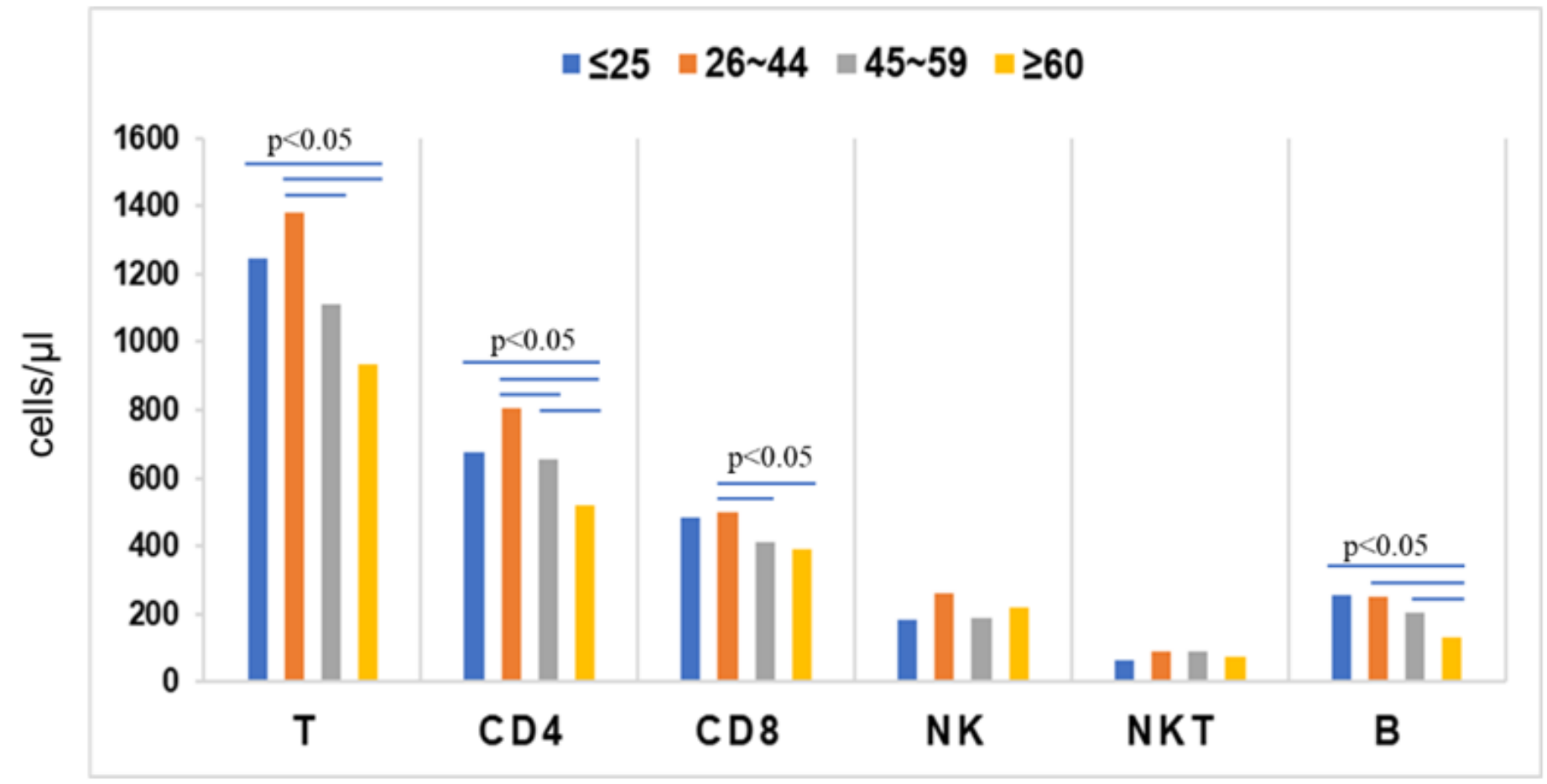

Figure 3 
Comparisons of lymphocyte subset absolute counts among four age groups in simple PTB patients. The blue bars marked the significant differences among different groups $(p<0.05)$. The $Y$ axis represented the mean values of the lymphocyte subsets counts (cells/ $\mu \mathrm{l}$ ) and the $\mathrm{X}$ axis represented the lymphocyte subsets in four age-groups.

A

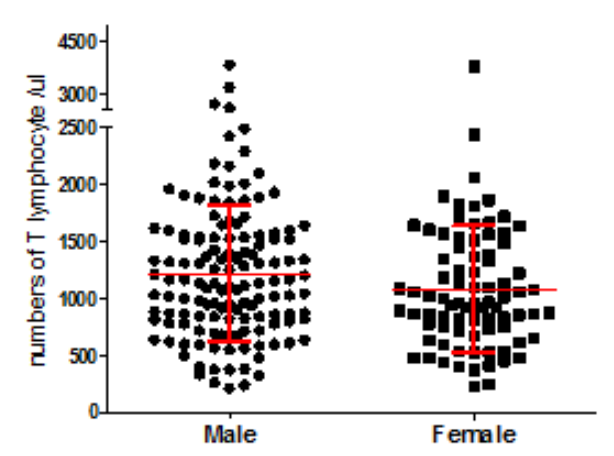

D

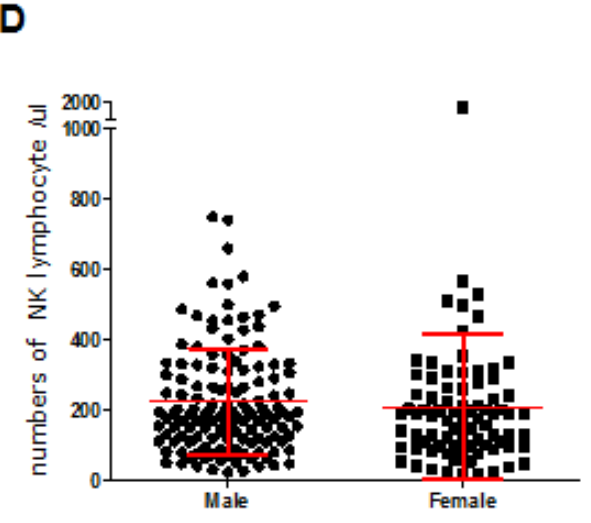

B

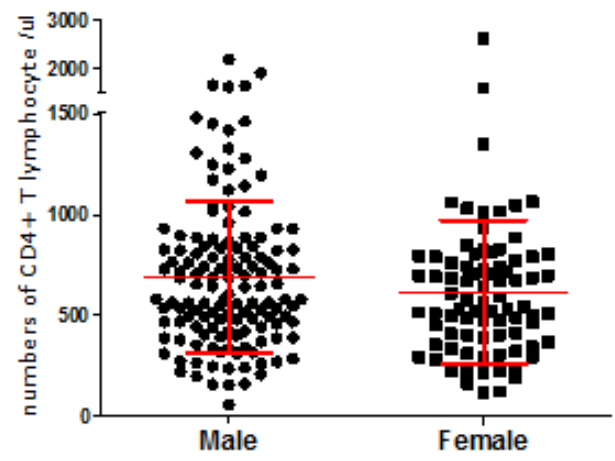

E

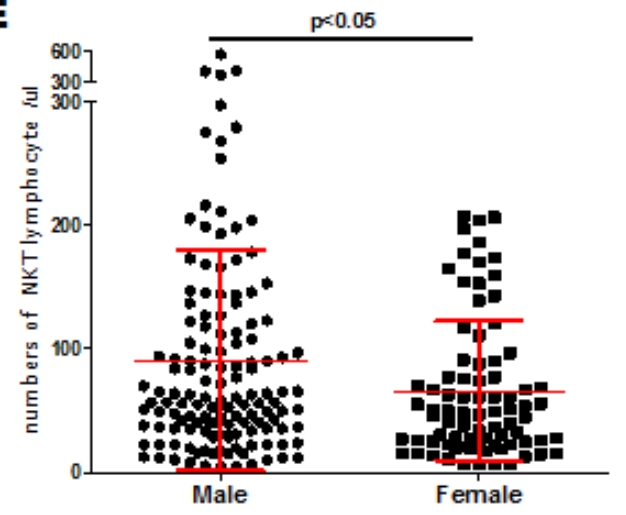

C

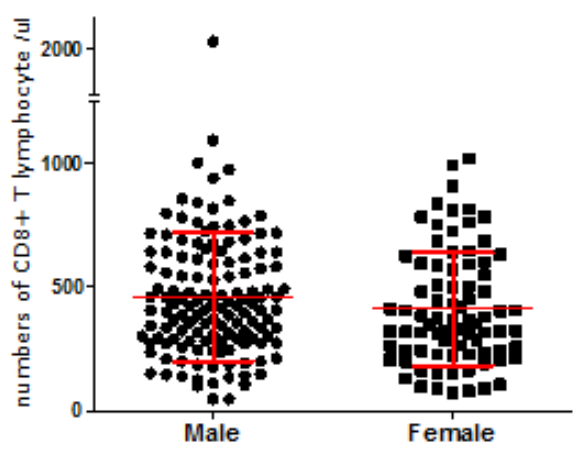

$\mathbf{F}$

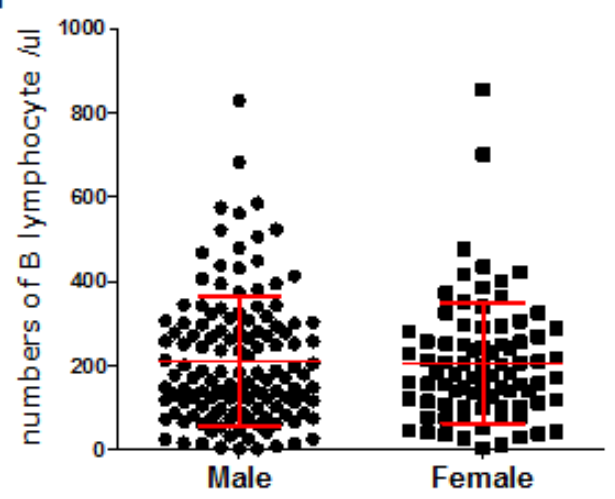

Figure 4

Comparisons of lymphocyte subset absolute counts between the gender groups in simple PTB patients. (A) T lymphocytes (CD3+); (B) CD4+ T lymphocytes (CD3+ CD4+ CD8-); (C) CD8+ T lymphocytes (CD3+ CD4- CD8+); (D) Natural killer (NK) cells (CD16\&56+ CD3-); (E) NKT cells (CD16\&56+CD3+); (F) B lymphocytes (CD3- CD19+). The black bar marked the significant difference $(p<0.05)$. The red bars marked the mean \pm SD levels of lymphocyte subset absolute counts in each group. 

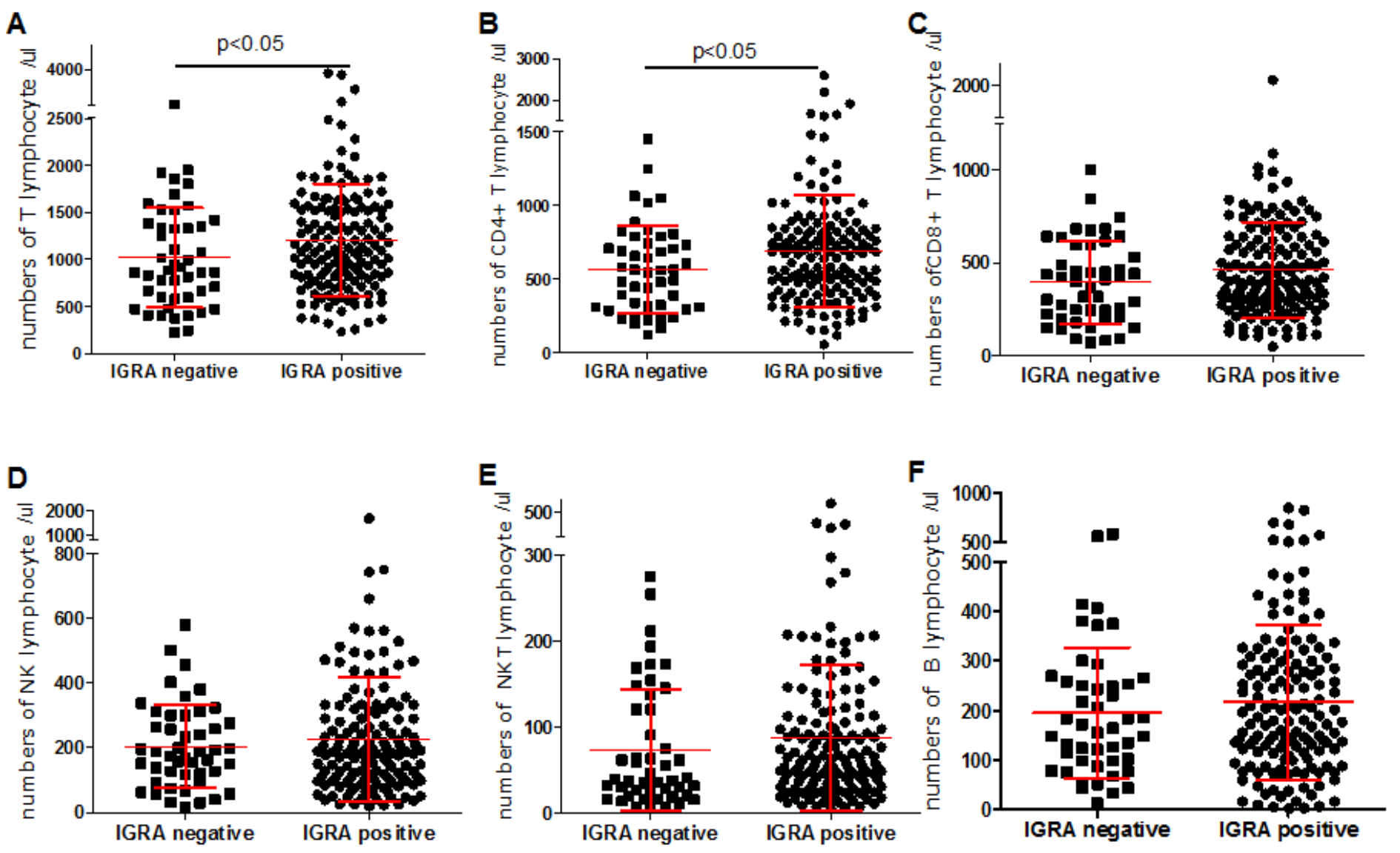

Figure 5

Comparisons of lymphocyte subset absolute counts between the IGAR-positive and IGAR-negative groups in simple PTB patients. (A) T lymphocytes (CD3+); (B) CD4+ T lymphocytes (CD3+ CD4+ CD8-); (C) CD8+ T lymphocytes (CD3+ CD4- CD8+); (D) Natural killer (NK) cells (CD16\&56+ CD3-); (E) NKT cells (CD16\&56+CD3+); (F) B lymphocytes $(C D 3-C D 19+)$. The black bar marked the significant difference $(p<0.05)$. The red bars marked the mean $\pm S D$ levels of lymphocyte subset absolute counts in each group. 
A
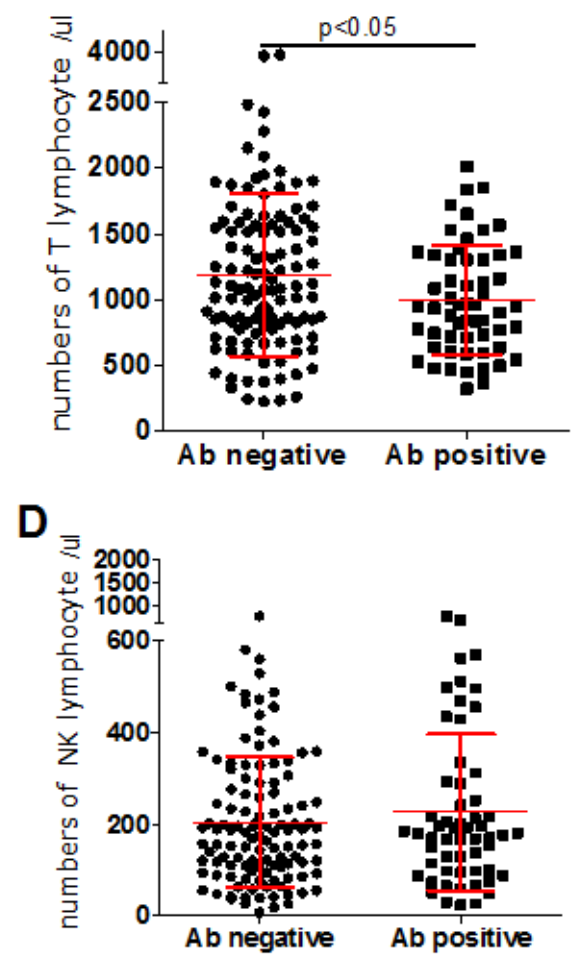

B

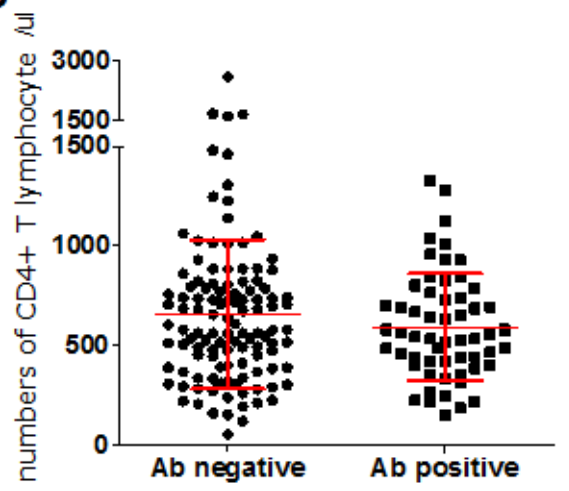

E

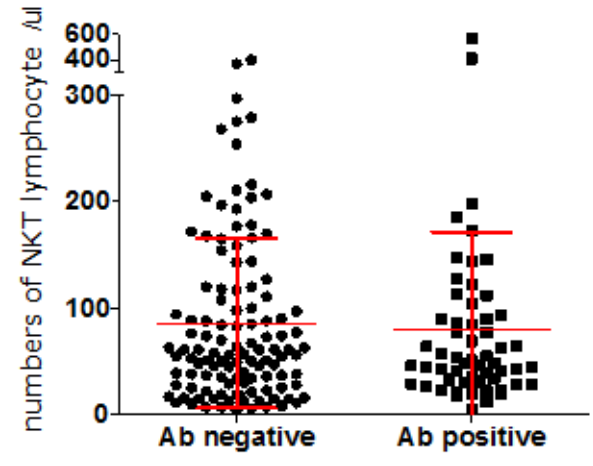

C

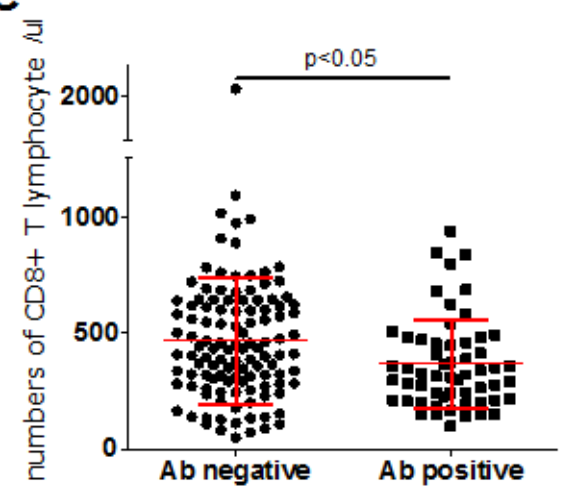

$\mathbf{F}$

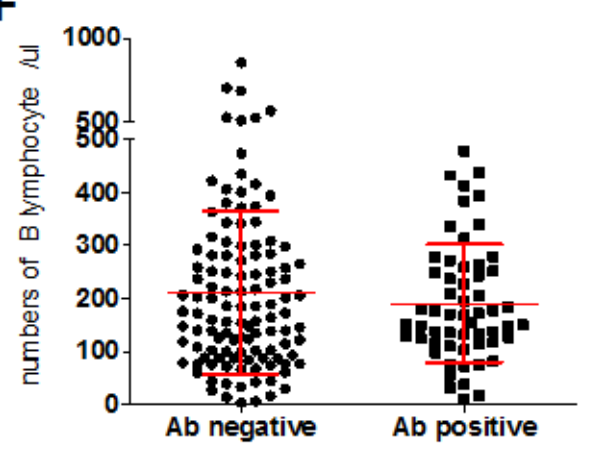

Figure 6

Comparisons of lymphocyte subset absolute counts between the IgG antibody response negative and positive groups in simple PTB patients. (A) T lymphocytes (CD3+); (B) CD4+ T lymphocytes (CD3+ CD4+ CD8-); (C) CD8+ T lymphocytes (CD3+ CD4- CD8+); (D) Natural killer (NK) cells (CD16\&56+ CD3-); (E) NKT cells (CD16\&56+CD3+); (F) $B$ lymphocytes (CD3- CD19+). The black bar marked the significant difference $(p<0.05)$. The red bars marked the mean \pm SD levels of lymphocyte subset absolute counts in each group. 
A
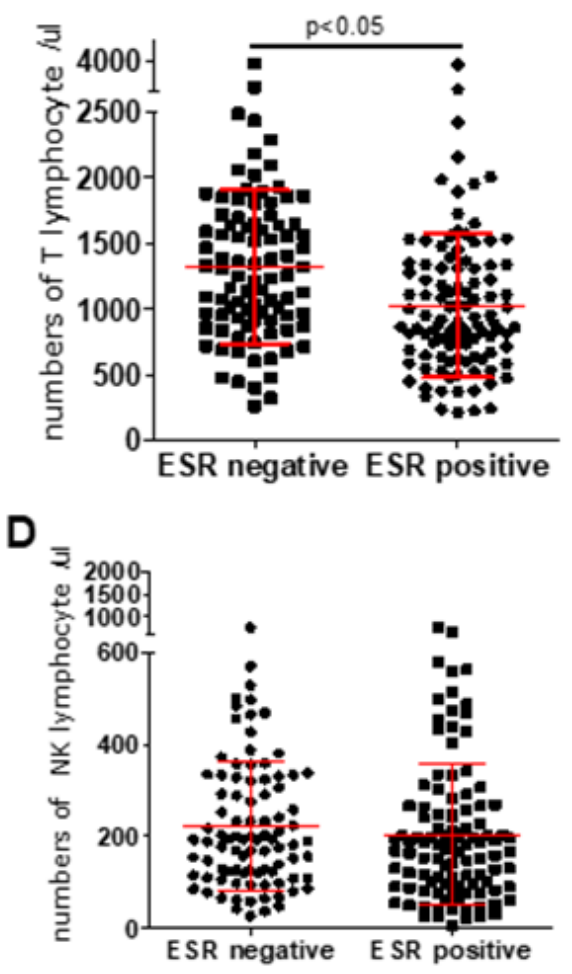

B

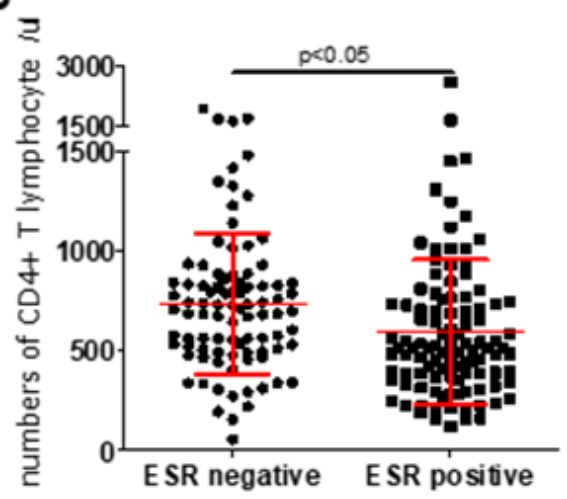

$E$

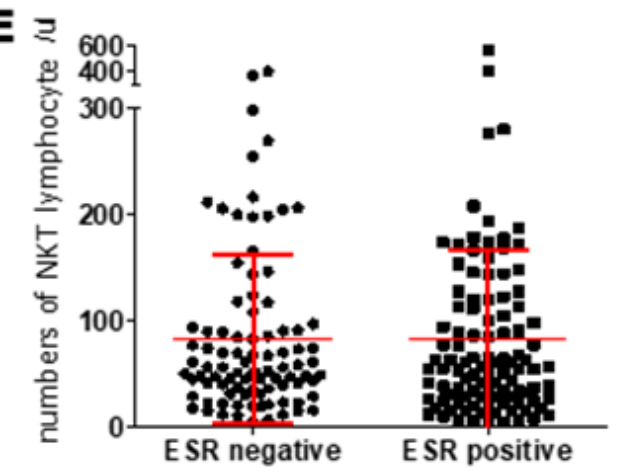

C

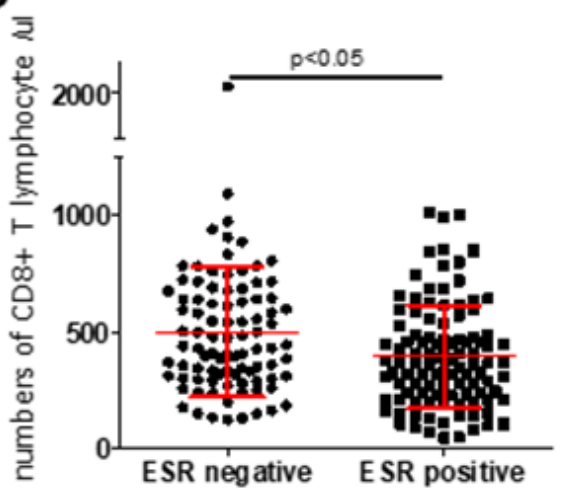

$\mathbf{F}$

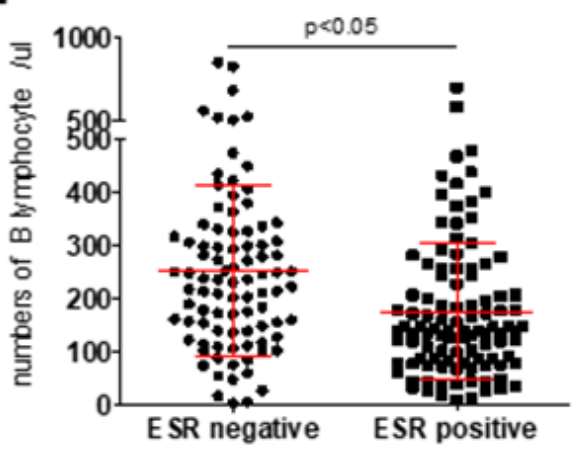

Figure 7

Comparisons of lymphocyte subset absolute counts between the ESR (erythrocyte sedimentation rate) negative and positive groups in simple PTB patients. (A) T lymphocytes (CD3+); (B) CD4+ T lymphocytes (CD3+ CD4+ CD8-); (C) CD8+ T lymphocytes (CD3+ CD4- CD8+); (D) Natural killer (NK) cells (CD16\&56+ CD3-); (E) NKT cells (CD16\&56+CD3+); ( $F)$ B lymphocytes (CD3- CD19+). The black bar marked the significant difference $(p<0.05)$. The red bars marked the mean \pm SD levels of lymphocyte subset absolute counts in each group. 
A
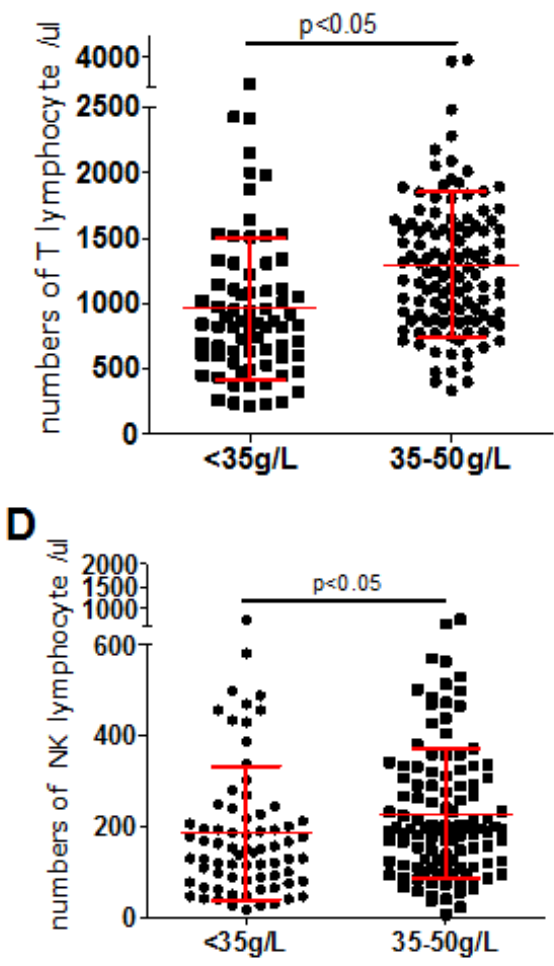

B

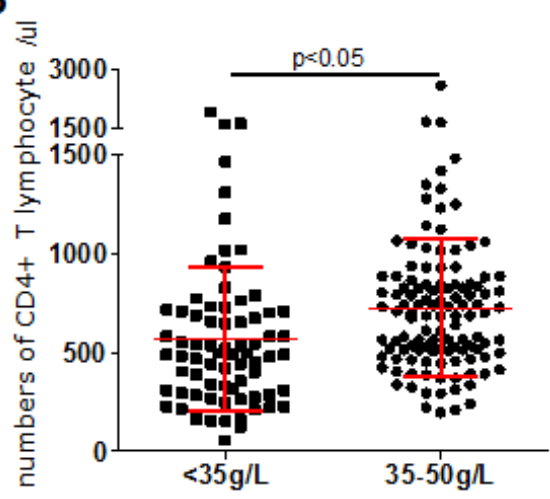

$\mathbf{E}$

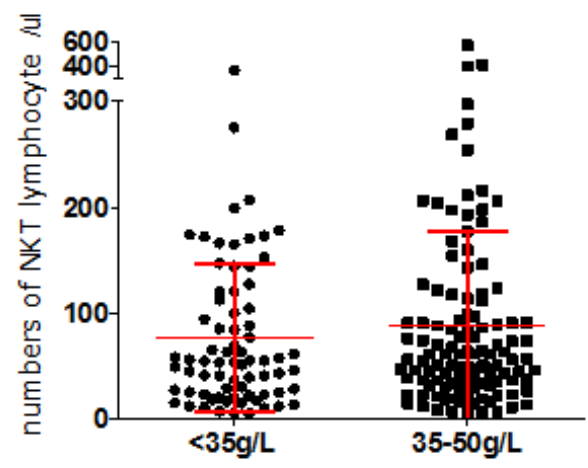

C

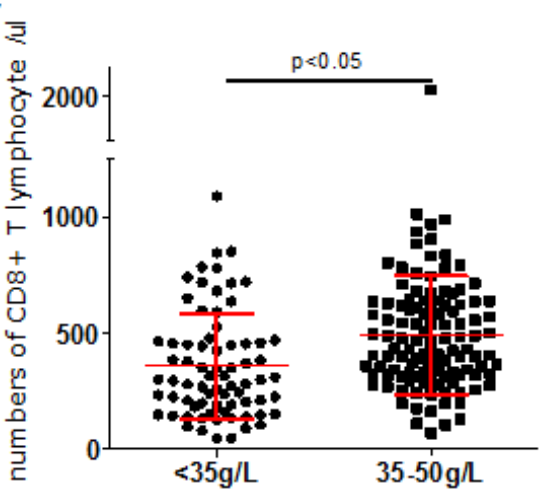

$\mathbf{F}$

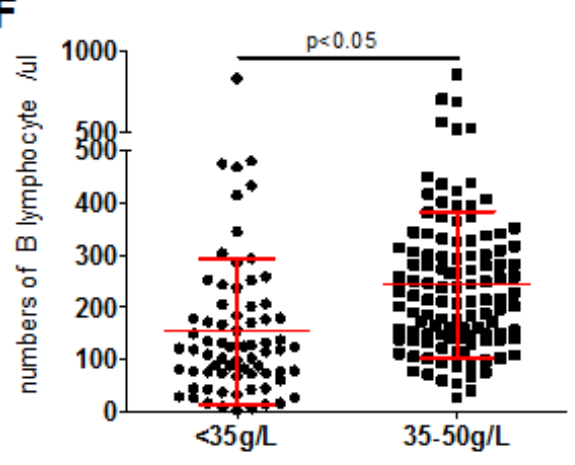

Figure 8

Comparisons of lymphocyte subset absolute counts between the low and normal serum Alb groups in simple PTB patients. (A) T lymphocytes (CD3+); (B) CD4+ T lymphocytes (CD3+ CD4+ CD8-); (C) CD8+ T lymphocytes (CD3+ CD4- CD8+); (D) Natural killer (NK) cells (CD16\&56+ CD3-); (E) NKT cells (CD16\&56+CD3+); (F) B lymphocytes (CD3- CD19+). The black bar marked the significant difference $(p<0.05)$. The red bars marked the mean \pm SD levels of lymphocyte subset absolute counts in each group. 

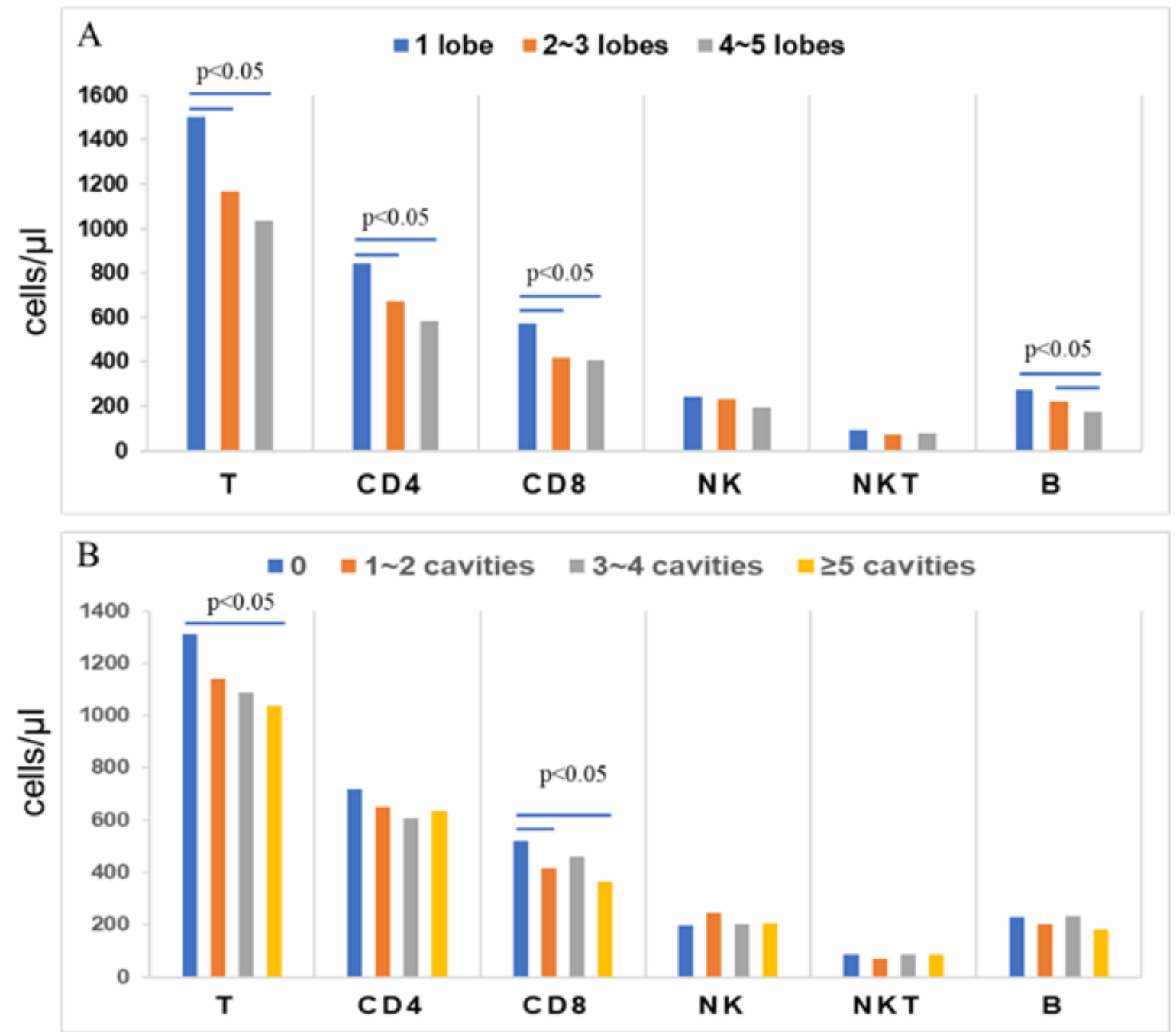

Figure 9

Comparisons of lymphocyte subset absolute counts respectively among the different pulmonary lesion lobe groups (A) and among the different pulmonary cavity groups (B) in simple PTB patients. The blue bars marked the significant difference $(p<0.05)$. The $Y$ axis represented the mean values (cells/ $\mu l)$ of the lymphocyte subsets and the $X$ axis represented the lymphocyte subset groups. 
A
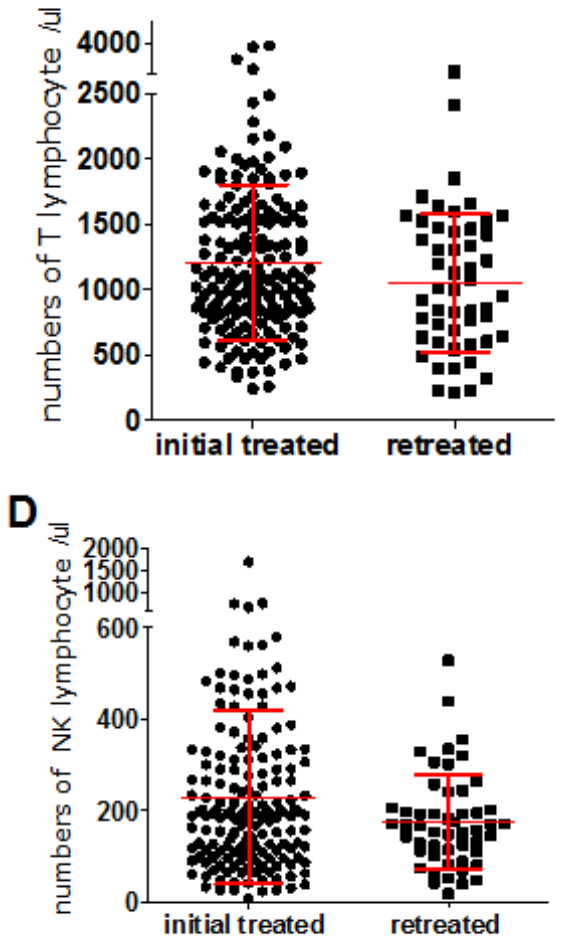

B

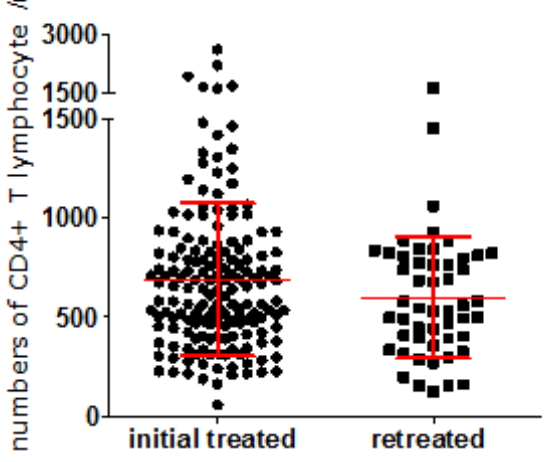

$\mathrm{E}$

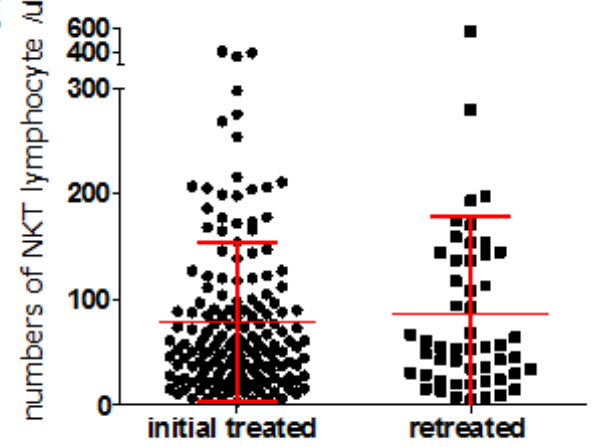

C

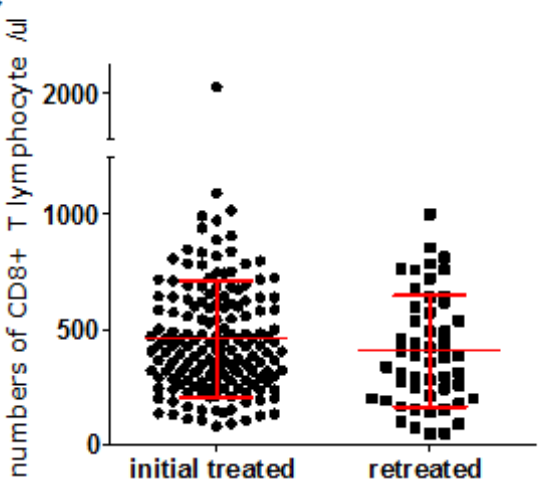

$\mathbf{F}$

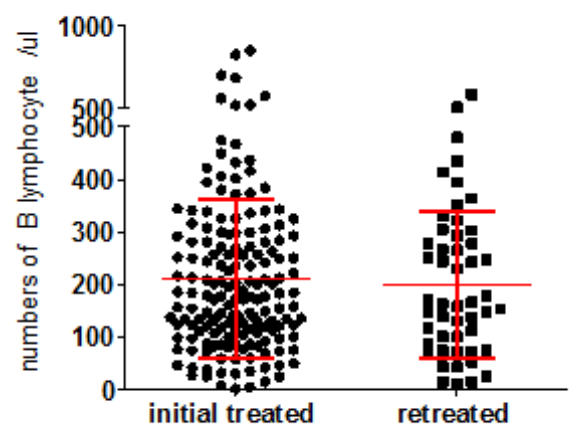

Figure 10

Comparisons of lymphocyte subset absolute counts between the initial treated and retreated groups in simple PTB patients. (A) T lymphocytes (CD3+); (B) CD4+ T lymphocytes (CD3+ CD4+ CD8-); (C) CD8+ T lymphocytes (CD3+ CD4- CD8+); (D) Natural killer (NK) cells (CD16\&56+ CD3-); (E) NKT cells (CD16\&56+CD3+); (F) B lymphocytes (CD3- CD19+). The black bar marked the significant difference $(p<0.05)$. The red bars marked the mean \pm SD levels of lymphocyte subset absolute counts in each group. 

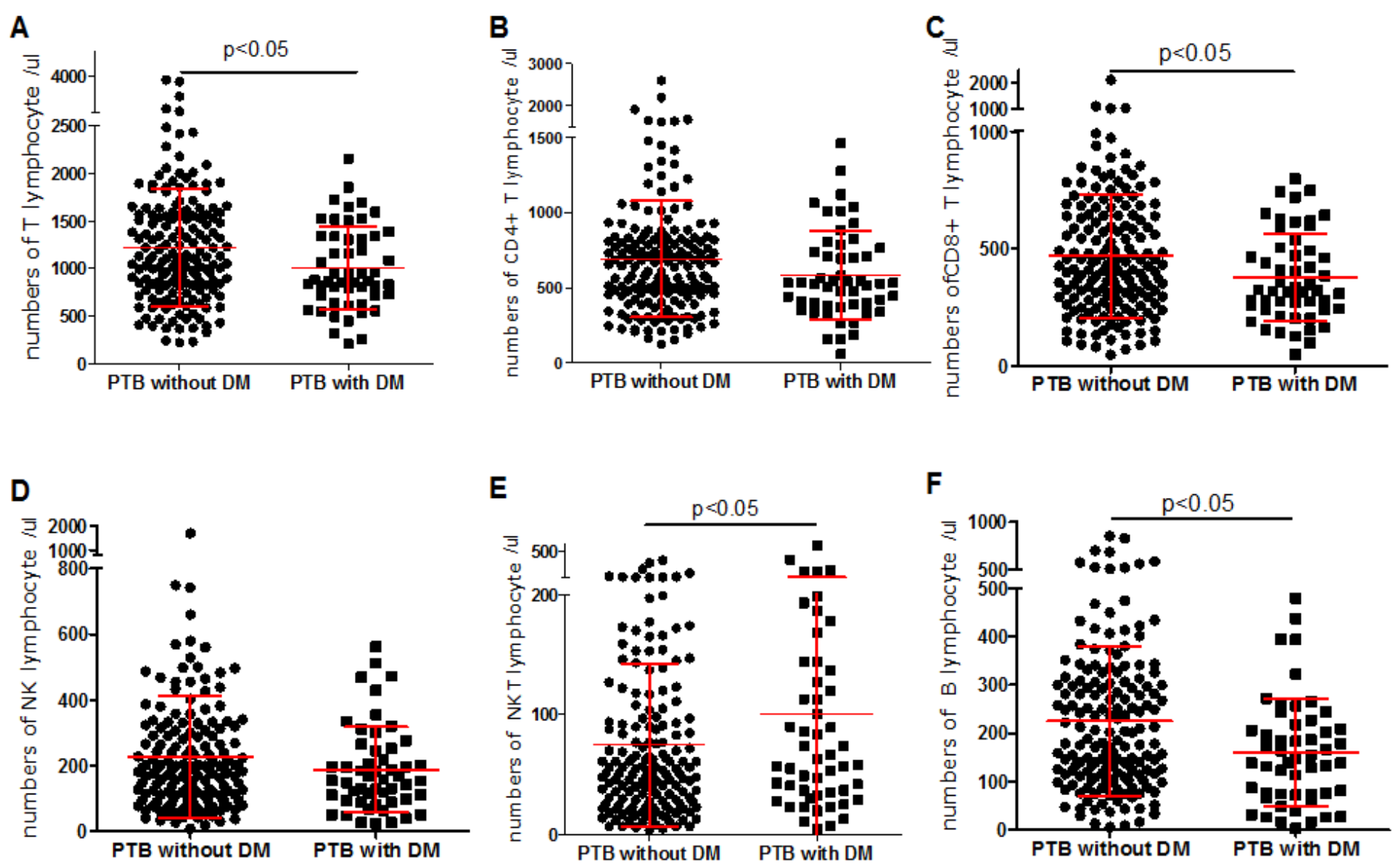

Figure 11

Comparisons of lymphocyte subset absolute counts between the PTB patients with and without Diabetes Meletus (DM) groups. (A) T lymphocytes (CD3+); (B) CD4+ T lymphocytes (CD3+ CD4+ CD8-); (C) CD8+ T lymphocytes (CD3+ CD4- CD8+); (D) Natural killer (NK) cells (CD16\&56+ CD3-); (E) NKT cells (CD16\&56+CD3+); (F) B lymphocytes $(C D 3-C D 19+)$. The black bar marked the significant difference $(p<0.05)$. The red bars marked the mean \pm SD levels of lymphocyte subset absolute counts in each group. 
A
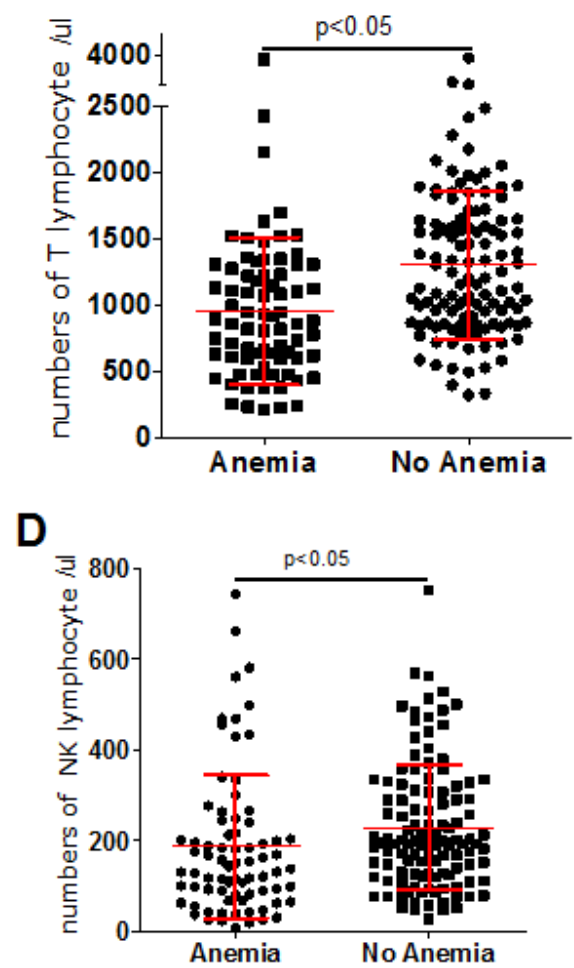

B

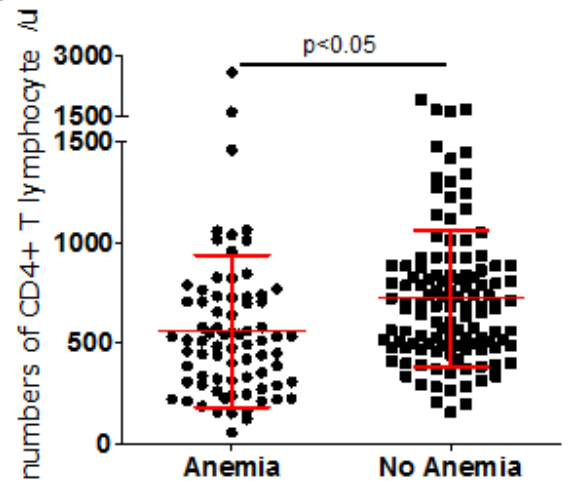

$E \equiv$

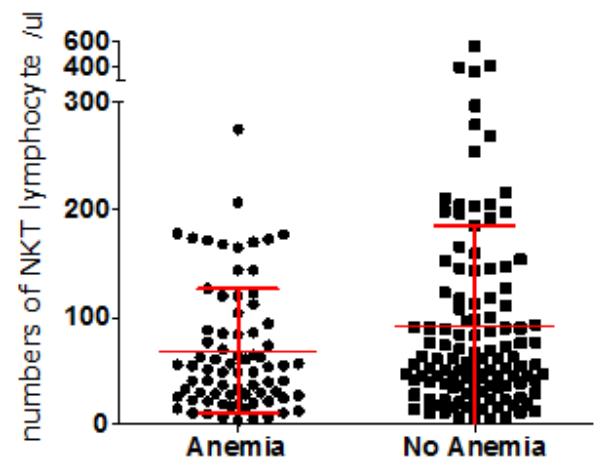

C

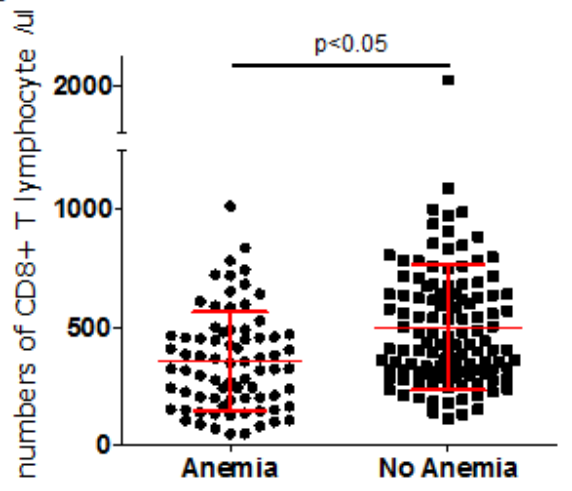

$\mathbf{F}$

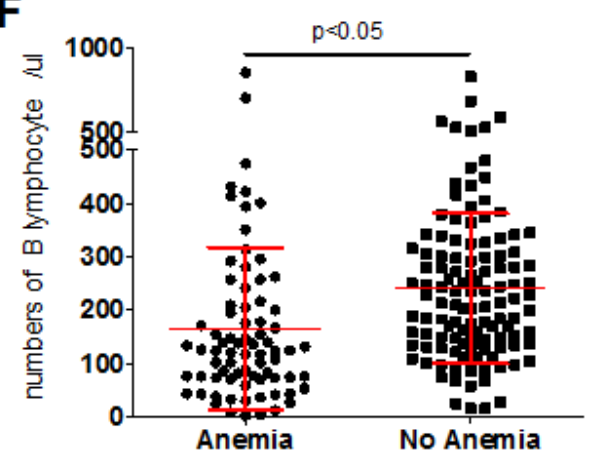

Figure 12

Comparisons of lymphocyte subset absolute counts between the simple PTB patient groups with anemia and without anemia. (A) T lymphocytes (CD3+); (B) CD4+ T lymphocytes (CD3+ CD4+ CD8-); (C) CD8+ T lymphocytes (CD3+ CD4- CD8+); (D) Natural killer (NK) cells (CD16\&56+ CD3-); (E) NKT cells (CD16\&56+CD3+); (F) B lymphocytes (CD3- CD19+). The black bar marked the significant difference $(p<0.05)$. The red bars marked the mean \pm SD levels of lymphocyte subset absolute counts in each group. 